\title{
INCLUSÃO DO CONTROLE DE DEFLÚVIO EM MODELOS DE GESTÃO FLORESTAL: UM ESTUDO NO VALE DO PARAÍBA - SP
}

\section{TATIANA MAHALEM DO AMARAL}

\begin{abstract}
Dissertação apresentada à Escola Superior de Agricultura "Luiz de Queiroz", Universidade de São Paulo, para obtenção do título de Mestre em Recursos Florestais, Área de Concentração: Recursos Florestais, com opção em Manejo de Florestas de Produção
\end{abstract}

PIRACICABA

Estado de São Paulo - Brasil

Fevereiro - 2002 


\title{
INCLUSÃO DO CONTROLE DE DEFLÚVIO EM MODELOS DE GESTÃO FLORESTAL: UM ESTUDO NO VALE DO PARAIIBA - SP
}

\author{
TATIANA MAHALEM DO AMARAL \\ Engenheiro Florestal
}

Orientador: Prof. Dr. LUIZ CARLOS ESTRAVIZ RODRIGUEZ

\begin{abstract}
Dissertação apresentada à Escola Superior de Agricultura "Luiz de Queiroz", Universidade de São Paulo, para obtenção do título de Mestre em Recursos Florestais, Área de Concentração: Recursos Florestais, com opção em Manejo de Florestas de Produção
\end{abstract}

PIRACICABA

Estado de São Paulo - Brasil

Fevereiro - 2002 
Dados Internacionais de Catalogação na Publicação (CIP)

DIVISÃO DE BIBLIOTECA E DOCUMENTAÇÃO - ESALQ/USP

\author{
Amaral, Tatiana Mahalem do \\ Inc lusão do controle de deflúvio em modelos de gestão florestal : um \\ estudo no Vale do Paraíba - SP / Tatiana Mahalem do Amaral. - - \\ Pirac icaba, 2002. \\ $64 \mathrm{p}$. \\ Dissertação (mestrado) - - Escola Superior de Agricultura Luiz de \\ Queiroz, 2002. \\ Bibliografia. \\ 1. Administração florestal 2. Bacia hidrográfica 3. Deflúvio 4. Euca lip to \\ 5. Planejamento florestal 6. Produção vegetal 7. Recursos hídric os I. Título \\ CDD 634.928
}


Aos meus pais, Eduardo e Jane

e à minha irmã, Taís

minha base, meu porto, minha vida.

Ao Leandro,

meu companheiro de todos os momentos.

Ao professor Luiz,

um grande amigo, um grande mestre. 


\section{AGRADECIMENTOS}

À Deus, pela vida.

Ao professor Luiz Carlos, pela confiança, oportunidade e dedicação durante esta etapa.

Ao Fabiano, pela paciência, ajuda e amizade.

À Lana, pela amizade verdadeira.

À ESALQ/USP, pela minha formação.

À FAPESP pelo apoio financeiro.

À Votorantim Celulose e Papel S/A, principalmente aos engenheiros Fausto e Cláudio pela disponibilização dos dados utilizados no trabalho.

Aos professores Walter de Paula Lima e Maria José Brito Zakia, pela parceria na criação do trabalho e constantes sugestões para melhoria do mesmo.

Ao professor José Vicente Caixeta Filho, pelas sugestões apresentadas no exame de qualificação.

Aos colegas do Laboratório de Métodos Quantitativos, pela convivência.

“De tudo, ficaram três coisas:

A certeza de que estamos sempre recomeçando...

A certeza de que precisamos continuar...

A certeza de que seremos interrompidos antes de terminar...

Portanto devemos fazer da interrupção um caminho novo...

Da queda um passo de dança...

Do medo, uma escada...

Do sonho, uma ponte...

Da procura, um encontro..." (Fernando Pessoa) 


\section{SUMÁRIO}

Página

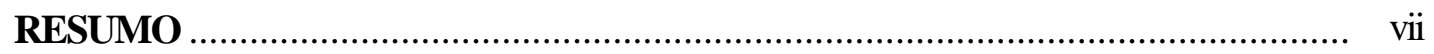

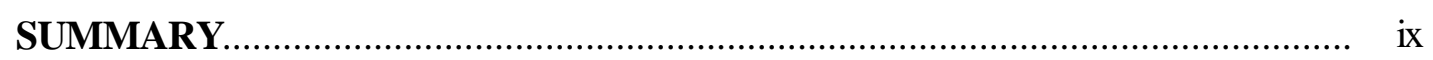

1 INTRODUÇÃ

1.1 Objetivo e hipótese ................................................................................ 2

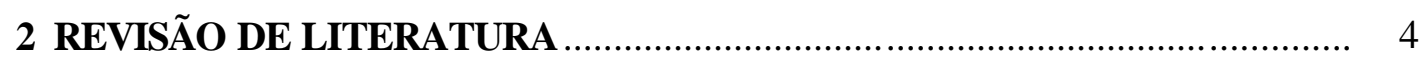

2.1 Gestão e planejamento florestal...................................................................... 4

2.2 A busca da sustentabilidade florestal................................................................ 5

2.3 A microbacia e os indicadores hidrológicos............................................................ 8

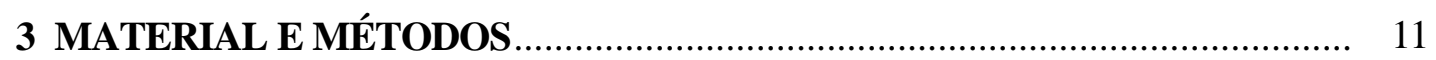

3.1 Formulação do modelo básico de programação linear .............................................. 11

3.1.1 Função objetivo........................................................................................... 11

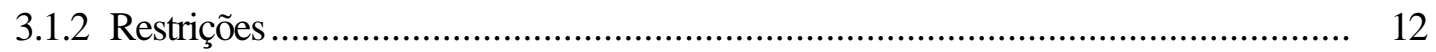

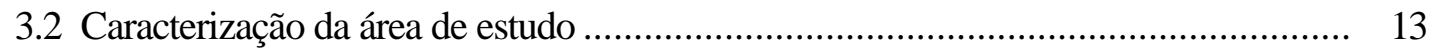

3.2.1 Caracterização das fazendas e seus plantios flor estais .......................................... 14

3.2.2 Fazenda Bela Vista III ............................................................................. 16

3.2.3 Custos das atividades florestais praticados pela empresa ................................... 17

3.3 Construção do modelo básico de programação linear e suas variações ....................... 20

3.3.1 Cálculo dos coeficientes da função objetivo e geração das alternativas de

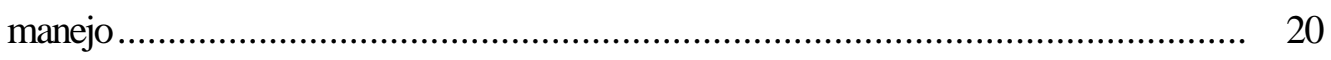

3.3.2 Montagem da restrição hidrológica............................................................. 25

3.3.2.1 Cálculo dos coeficientes técnicos do deflúvio ................................................ 27 


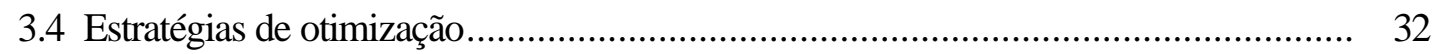

3.5 Elaboração e comparação dos planos de corte......................................................... 32

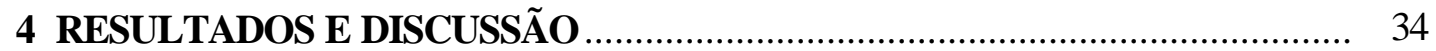

4.1 Valor total do projeto, fluxo de produção de madeira e deflúvio ................................... 34

4.2 Elaboração e comparação dos plano de corte ……................................................. 40

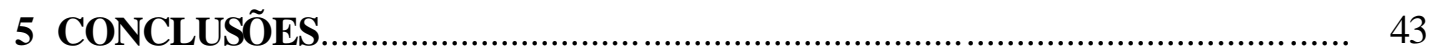

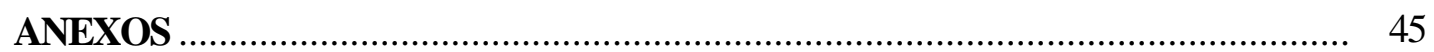

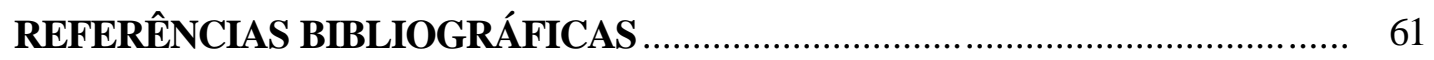




\title{
INCLUSÃO DO CONTROLE DE DEFLÚVIO EM MODELOS DE GESTÃO FLORESTAL: UM ESTUDO NO VALE DO PARAÍBA - SP
}

\author{
Autora: TATIANA MAHALEM DO AMARAL
}

Orientador: Prof. Dr. LUIZ CARLOS ESTRAVIZ RODRIGUEZ

\section{RESUMO}

Baseado em uma relação simples entre volume de madeira em pé e deflúvio observados em duas microbacias com povoamentos de eucaliptos, este estudo compara os resultado obtido por três modelos de programação linear: (i) um que maximiza o valor total do projeto, com restrições de área e de produção de madeira; e (ii) dois outros modelos que fazem o mesmo com o controle do indicador hidrológico (deflúvio). A hipótese principal do trabalho é que a consideração do indicador hidrológico no planejamento de povoamentos florestais afeta significativamente os regimes de manejo, alterando os planos de colheita e o fluxo de produção de madeira. A área de estudo é constituída por trinta e cinco unidades de gestão, com áreas que variam de 30 ha a 800 ha e diferentes produtividades, totalizando 8007 ha. Regimes de talhadia simples, baseados em dois cortes, diferem entre si apenas pela idade em que a floresta é cortada. O nível de deflúvio e o volume de madeira em pé foram estatisticamente ajustados utilizando um modelo exponencial baseado na coleta de dados na área de estudo. $O$ resultado da relação entre deflúvio e estoque de madeira mostra uma curva que é convexa em relação a origem e negativamente inclinada. Como as áreas de corte raso e florestas novas produzem fluxos de deflúvio elevados, a regularização do mesmo foi 
incluída como restrição no modelo. Os resultados obtidos permitem concluir que a inclusão das restrições hidrológicas no modelo afetou o manejo, alterou o fluxo de produção de madeira e resultou em valores presente líquidos globais diferentes para cada modelo, confirmando então a principal hipótese do trabalho. A água e a madeira são dois recursos de grande importância e devem ser controlados simultaneamente. As técnicas de programação linear se mostraram eficientes para gerir o manejo desses recursos. 


\section{INCLUSION OF WATER OUTFLOW CONTROL IN FOREST MANAGEMENT MODELS: A STUDY CASE IN VALEDO PARAÍBA - SP}

Author: TATIANA MAHALEM DO AMARAL Adviser: Prof. Dr. LUIZ CARLOS ESTRAVIZ RODRIGUEZ

\section{SUMMARY}

Based on a simple relationship between growing stock and water outflow observed on two watersheds planted with Eucalyptus in Brazil, this study compares the results obtained by three different linear programming formulations: (i) one that maximizes the net present value simply constrained by area and a regulated wood production flow; and (ii) two other models that maximize the net present value constrained by area, a regulated wood production flow, and specific hydrological goals. As one of the hypothesis, it is stated that the inclusion of hydrological constraints in the model will affect significantly the selection of forest regimes, altering the final harvestscheduling plan and the wood production flow. Thirty-five management units, with areas ranging from 30 ha to 800 ha and different site indexes, form an Eucalyptus plantation project with 8.007 hectares. Simple coppice regimes, based on two clear cuts followed by the complete renewal of the plantation, differ one to another only by the age at which the clear cut is scheduled. Water outflow levels and stock volume levels were statistically adjusted according to an exponential model based on data collected on watersheds in the study area. The resulting relationship between outflow and stock volume shows a curve that is convex to the origin and negatively sloped. Given that 
clear-cut areas produce highly undesirable water outflows to the watershed, maximum water outflow limits had to be included as constraints in the model. Results obtained by the hydrologically constrained model confirm the hypothesis that the wood production flow is affected by limiting water outflow. The study allowed the attribution of economical values to different levels of limitations in terms of total water production in the watershed. Water and wood, two of the most important assets to a forester, should be managed together. Linear programming modeling techniques, proved to be very efficient when managing such resources. 


\section{INTRODUÇÃO}

Nas organizações florestais o grau de complexidade das interações temporais e espaciais sobre a produção assume uma magnitude muito ampla. O planejamento isolado das ações silviculturais para cada povoamento florestal em sua individualidade, não é suficiente para possibilitar um gerenciamento adequado em toda a floresta. Assim, quando o propósito é realizar o planejamento da produção para uma empresa florestal, freqüentemente faz-se uso de técnicas matemática de apoio da decisão (Ahrens, 1997).

A utilização dos modelos matemáticos de programação linear e sistemas integrados de computação, que simulam o comportamento de sistemas naturais, são ideais para a obtenção de informações e configurações de cenários para o planejamento florestal, visando a otimização da produção madeireira, dos retornos financeiros e auxiliando a tomada de decisão na organização (Falcão \& Borges, 1999).

Pesquisas recentes que revêm o processo de decisão florestal, incluem preocupações de caráter ambiental, evidenciando a necessidade de intervenções mais controladas nos plantios florestais e garantindo a aplicação do princípio da sustentabilidade na gestão florestal.

Nas empresas florestais, a preocupação com questões ambientais somente foi constatada quando esta variável passou a influenciar positiva ou negativamente suas atividades e sua performance. Assim sendo, os recursos naturais passaram a ser alvo de monitoramento e começaram a ser considerados nos processos de decisão estratégica e no plano de investimento da empresa. 
Em abordagens tradicionais, o processo de decisão é orientado por modelos de gestão que privilegiam indicadores relacionados com questões econômicas e volumétricas. No entanto, as preocupações com a qualidade do ambiente, impactos sobre os recursos naturais (água, solo, ar, biodiversidade etc) e uso não degradável dos fatores de produção levam a necessidade de inclusão de novos indicadores nos modelos de gestão, ou seja, é necessário considerar de modo simultâneo os impactos da gestão sobre a sustentabilidade de fluxos de produção e sobre a sustentabilidade do próprio ecossistema florestal.

Segundo Lima \& Zakia (1996), não há mais lugar para um empreendimento que não esteja fundamentado na questão da sustentabilidade ambiental. $\mathrm{O}$ aprimoramento das práticas de manejo florestal, permitindo reduzir cada vez mais os possíveis impactos de suas atividades sobre o meio ambiente são preceitos básicos que estão embutidos na Agenda 21 (documento contendo compromissos para mudança do padrão de desenvolvimento no século 21). Desta forma, o problema ambiental, em todos os possíveis desdobramentos, não pode mais ser desconsiderado em qualquer projeto florestal (Lima \& Zakia, 1998).

\subsection{Objetivo e hipótese}

O objetivo deste trabalho foi desenvolver um modelo matemático de gestão florestal que incorporou um indicador hidrológico do manejo de microbacias. $\mathrm{O}$ indicador hidrológico que foi inserido no modelo foi o deflúvio, o qual se refere à produção de água na floresta. Este modelo teve como finalidade auxiliar o processo de tomada de decisão nas atividades de manejo e planejamento da produção florestal, indicando o tipo de intervenção adequada para cada povoamento, a época e intensidade ideais para a sua realização em uma empresa florestal, buscando sempre minimizar os impactos sobre o solo e recursos hídricos. Os custos de se implementar os planos gerados pelo modelo proposto também foram analisados. 
A principal hipótese deste estudo é:

- a consideração do indicador hidrológico no planejamento de povoamentos florestais voltados para o abastecimento industrial, afeta o manejo, alterando o fluxo de colheita e demais intervenções silviculturais, ou seja, ao se tomar a microbacia como unidade sistêmica de manejo, altera-se a forma como a unidade de gestão (talhão) é manejada.

O presente trabalho organiza-se em cinco capítulos, os quais estão estruturados da seguinte maneira:

1. Introdução: apresentação, justificativa, objetivo e hipótese do trabalho.

2. Revisão bibliográfica: a importância da gestão, planejamento e uso das técnicas de programação linear no setor florestal; a busca da sustentabilidade através do manejo de microbacias.

3. Materiais e métodos: descrição da formulação genérica do modelo básico de programação linear, seguindo da caracterização da área do estudo, e finalmente, as etapas da construção do modelo com a introdução do indicador hidrológico resultando em três variações sobre o modelo básico.

4. Resultados e discussão: comparação dos resultados provenientes dos modelos estudados.

5. Conclusões: as principais conclusões e recomendações para novas pesquisas. 


\section{REVISÃO DE LITERATURA}

\subsection{Gestão e planejamento florestal}

Um sistema de gestão florestal é aquele que define como deverão ocorrer as intervenções florestais em cada unidade de manejo sob o ponto de vista das conseqüências para a floresta como um todo (Rodriguez et al., 1997).

Em uma abordagem clássica, Davis \& Johnson (1987), identificaram três componentes no processo de definição de alternativas de gestão: a organização e classificação da área em unidades de gestão, de acordo com critérios de homogeneidade ecológica e produtiva; a definição da estrutura cronológica das intervenções possíveis em cada unidade, por forma de atingir os objetivos do tomador de decisões; a quantificação de fluxos de bens e serviços que decorrem das intervenções e a determinação do seu momento de ocorrência no tempo.

No passado, não havia grandes preocupações de caráter ambiental, os sistemas de gestão não incluíam quaisquer restrições desse tipo, tendendo para uma otimização do volume da madeira explorada e para uma otimização econômica do empreendimento.

Smith \& Thwaites (1998), referem-se a uma estrutura de análise de sustentabilidade em três níveis: o da unidade de manejo, o da organização e o da microbacia hidrográfica que abrange as áreas sob manejo. Os autores argumentam que os indicadores capazes de avaliar a sustentabilidade ecológica das intervenções são definidos de acordo com a gestão dos recursos hidrológicos da microbacia. 
Segundo Borges (1996), a utilidade de um sistema de gestão decorre da possibilidade de oferecer informações adicionais para o conhecimento da realidade sobre a qual se pretende intervir. A dimensão das áreas envolvidas, os horizontes de planejamento considerados e as incertezas relativas aos impactos das intervenções humanas sobre o ecossistema, tornam aquela informação adicional particularmente relevante. Assim novas tendências de evolução sócio econômica determinam uma alteração na base de recursos naturais a ser considerada no planejamento florestal. A importância atribuída à biodiversidade, à proteção do solo e da água, aos valores estéticos, à oferta de oportunidade de lazer etc, definem um novo quadro para o planejamento dos recursos naturais.

Segundo Rodriguez \& Borges (1999), a gestão florestal amparada nas técnicas matemáticas de otimização é capaz de considerar simultaneamente, a meta de se atingir o manejo de uma floresta balanceada, a fase de transição para esta situação, além de questões econômicas, restrições operacionais e ambientais.

A programação linear é uma técnica de pesquisa operacional aplicada em larga escala em soluções de problemas de gestão de recursos florestais. O modelo linear permite a formalização de alguns objetivos e restrições comuns em recursos florestais e a sua solução oferece informações interessante para a análise de decisão (Falcão \& Borges, 1999).

\subsection{A busca da sustentabilidade florestal}

Como elemento central da gestão dos recursos florestais, a sustentabilidade colocou definitivamente a questão do longo prazo na aplicação de modelos de gestão florestal, mas simultaneamente pôs em evidência a necessidade de intervenções mais controladas sobre os ecossistemas florestais. A questão que se deve colocar é a de saber o que pretendemos sustentar, por que e para quem, e quais os objetivos de gestão e valores que fundamentam os mesmos (Carvalho, 1998). 
O mesmo autor, comenta que a sustentabilidade implica a escolha de alternativas em vários níveis, desde os instrumentos de ordenamento do território até aos planos nas unidades de gestão florestal.

O "princípio da precaução", consagrado desde 1993 no Tratado de Maastrish, estabelece que, em caso de riscos de danos graves ou irreversíveis no ambiente, a ausência de certezas científicas, não deve servir de pretexto para adiar a adoção de medidas efetivas de prevenção à degradação ambiental.

Essas medidas preventivas representam custos para o empreendimento, no entanto, ainda hoje o "custo zero" dos serviços e recursos naturais conduz o sistema de mercado à hiperexploração do meio ambiente. O meio ambiente ao desempenhar funções imprescindíveis a vida humana apresenta, valor econômico positivo mesmo que não refletido diretamente pelo funcionamento do mercado. Portanto, não é correto tratálo como se tivesse valor zero, correndo o risco de uso excessivo ou até mesmo de sua completa degradação (Marques e Comune, 1997).

Segundo Musetti (2001), a água, independente do reconhecimento jurídico, é um bem de valor ambiental e, dependendo da situação de fato (água do rio, água do córrego, água do mar, etc.), pode ter valor turístico, espeleológico, dentre outros. Com o advento da Lei $n^{0}$ 9.433, de 08/01/97, a água (bem ambiental) nacional passou a ter valor econômico reconhecido pelo ordenamento jurídico (art. $1^{\mathrm{o}}$, II).

O desenvolvimento de novos paradigmas em gestão florestal sustentável desafia os profissionais da área. Nesse novo contexto, o tomador de decisões é obrigado a considerar um volume imenso de dados e de informações, e a responder de forma rápida e eficiente às várias solicitações. Consequentemente, os modelos matemáticos de gestão e as respectivas aplicações tecnológicas tornam-se instrumentos muito úteis para o sucesso da intervenção florestal (Borges, 1999).

De acordo com Carvalho (1998), o reconhecimento de que as condições de sustentabilidade se verificam nos ecossistemas florestais é um dado fundamental na qualificação ambiental de um sistema de gestão florestal. Assim, devem considerar-se critérios de avaliação da sustentabilidade, que definem elementos, condições essenciais, bem como o respectivo processo de avaliação. Os indicadores são medidas ou 
parâmetros quantitativos ou descritivos que, quando periodicamente controlados ou medidos, mostram a evolução na condição de um critério.

Varma et al. (2000), apresentaram uma ligação entre pesquisas já realizadas que consideraram o desenvolvimento de um sistema capaz de medir a sustentabilidade no planejamento florestal e a falta de esforços semelhantes para o monitoramento e utilização dos indicadores de sustentabilidade como sendo parte formal dos sistemas de gestão. Os autores integram os aspectos ecológicos, econômicos, e social no processo de tomada de decisão visando o alcance da sustentabilidade no planejamento florestal. Tal decisão envolve três objetivos específicos: definir o manejo florestal sustentável; encontrar uma maneira de quantificar a sustentabilidade considerando as dimensões espacial e temporal; e identificar estratégias para melhor gerir a floresta.

Hornbeck \& Smith (1997) apresentaram um modelo computacional de decisão, que auxilia os gestores florestais na escolha de melhores práticas de manejo visando a proteção dos recursos hídricos. Baseado no plano de corte da floresta, o modelo fornece ao gestor uma previsão dos impactos na qualidade e na quantidade de água, que ocorreriam se aquela prescrição fosse implementada, e ainda, fornece alternativas aproximadas de planejamento que minimizam os impactos sobre os recursos hídricos.

Nos chamados ecossistemas produtivos, especialmente aqueles relacionados com a produção agrícola e florestal, a análise da sustentabilidade poderá ser feita tomando-se por base o balanço hídrico das bacias hidrográficas. Para uma determinada bacia hidrográfica, a sustentabilidade produtiva com reflexos na sustentabilidade social e econômica poderá ser analisada também pela capacidade da produção primária. Nesse caso, o enfoque deve ser a biomassa comercializada ou seja os grãos, fibras, proteínas, frutos, flores, madeira etc. A possibilidade da manutenção da sustentabilidade desses ecossistemas de produção, dentro de uma escala de tempo de décadas ou séculos dependerá de avanços tecnológicos, de mudanças de estruturas sociais e institucionais, bem como da implementação de mecanismos de proteção de recursos naturais renováveis centrados na conservação do solo, dos recursos hídricos e da biodiversidade (Salati et al., 1999). 


\subsection{A microbacia e os indicadores hidrológicos}

Segundo Lima (1997), a microbacia, como unidade geomorfológica da paisagem, pode funcionar como uma manifestação espacialmente bem definida de um sistema natural aberto, dentro do qual as atividades florestais vão estar influenciando o seu funcionamento hidrológico (vazão, qualidade e quantidade de água, perdas de sedimentos etc.), e a sua biogeoquímica (balanço de nutrientes, potencial de produtividade do solo etc.). Esses fluxos e essas taxas estão dependentes do nível de biodiversidade, nas suas várias categorias ao longo da área.

O mesmo autor, reforça ainda que, a microbacia pode ser considerada como a unidade ecossistêmica de planejamento das atividades florestais, possibilitando a identificação de indicadores hidrológicos condizentes com o manejo sustentável.

O planejamento das atividades de manejo florestal baseado na manutenção dos valores da microbacia hidrográfica, constitui a ferramenta mais poderosa que se dispõe para alcançar o uso sustentável dos recursos florestais com o mínimo de impacto ambiental (Lima, 1996).

Stednick (1996), em seu artigo, "Monitoring the effects of timber harvest on annual water yield", discorre sobre o histórico dos estudos realizados em microbacias pareadas nos EUA. O autor afirma que o primeiro trabalho foi desenvolvido no Colorado em 1909 e avaliou os efeitos da colheita sobre o deflúvio. Depois disso centenas de estudos foram feitos a fim de avaliar os efeitos sobre o deflúvio a partir de: mudanças no uso da terra, distúrbios naturais, infestação de insetos, incêndios florestais, pastagens, conversão de vegetação, florestamento, tipo de sistema de colheita etc.

Lima (1997), em seu livro, "Impacto ambiental do eucalipto", apresenta dados sobre resultados obtidos em bacias hidrográficas, os quais mostram os efeitos do reflorestamento sobre a produção de água. É observado que os efeitos sobre a produção de água varia de acordo com a proporção da área da bacia que é submetida ao corte, ou que foi reflorestada. $\mathrm{O}$ autor também descreve sobre o histórico dos trabalhos realizados sobre o efeito da plantação de eucalipto sobre o balanço hídrico. 
O manejo florestal baseado nas condições de sustentabilidade tem como finalidade a produção de madeira para o abastecimento industrial, mas agora, preocupado também com a manutenção da diversidade estrutural e funcional ao longo de toda a paisagem florestal, protegendo a qualidade da água e a diversidade do meio aquático. Portanto, o entendimento dessas inter-relações e interações, significa, a busca de práticas que visem minimizar os impactos ao funcionamento do ecossistema (Lima, 1996).

Do ponto de vista ambiental, o reflorestamento com eucalipto é uma atividade bastante polêmica, sendo função de uma opinião pública generalizada que lhe atribui efeitos ecológicos adversos. Esses efeitos ecológicos podem ser minimizados, ou seja, eles podem estar ao alcance do controle do profissional florestal, através da adoção de práticas ambientalmente sadias de manejo florestal, conforme os preceitos do manejo florestal sustentável (Lima \& Zakia, 1998).

Tendo em vista esses efeitos ecológicos causados pelas florestas de eucaliptos, torna-se fundamental e indispensável o desenvolvimento e implementação de modelos matemáticos de gestão florestal que compreendam indicadores hidrológicos do manejo de microbacias hidrográficas permitindo assim considerar de modo simultâneo os impactos da gestão sobre a sustentabilidade de fluxos de produção bem como sobre a sustentabilidade do próprio ecossistema.

Tanto a quantidade como a qualidade das águas sofrem alterações em decorrência de causas naturais ou antrópicas. Entre as causas naturais que alteram o clima e, consequentemente, a disponibilidade de água, destacam-se as flutuações sazonais com período de um ano e outras com ciclo de médio e longo prazo, tais como o El Niño e os períodos glaciais, além de outras variações climáticas naturais. Entre as ações humanas que podem alterar o balanço hídrico, destacam-se em escala local e regional o desmatamento, a mudança do uso do solo, os projetos de irrigação e a construção de barragens. Na escala planetária, destaca-se a mudança climática global decorrente da alteração das características químicas da atmosfera com gases que promovem o "efeito estufa" (Salati et al., 1999). 
O mesmo autor salienta que a quantidade e a qualidade dos recursos hídricos, que escoam pelo canal principal de uma bacia hidrográfica em condições naturais, dependem do clima e das características físicas e biológicas dos ecossistemas que a compõem. Qualquer modificação nos componentes do clima ou da paisagem alterará a quantidade, a qualidade e o tempo de residência da água nos ecossistemas e, por sua vez, o fluxo da água e suas características no canal principal do rio.

A interação contínua e constante entre a litosfera, a biosfera e a atmosfera, acabam definindo um equilíbrio dinâmico para o ciclo da água, o qual define em última análise, as características e as vazões das águas. Esse equilíbrio depende basicamente (Salati et al., 1999):

- da quantidade e distribuição das precipitações: a quantidade de água proveniente das precipitações em uma bacia hidrográfica apresenta variações temporais e espaciais;

- do balanço de energia: a quantidade da água que é perdida através da evapotranspiração, depende da energia solar disponível, da natureza da vegetação e das características do solo;

- da geomorfologia: regula o tempo de permanência da água que depende da inclinação das secções transversais e longitudinal da bacia hidrográfica;

- da natureza e dimensão das formações geológicas: controla o armazenamento da água no solo, no subsolo e determina o fluxo de base dos afluentes e do canal principal;

- da vegetação natural que cobre a área: controla o balanço de energia, a infiltração da água, a evapotranspiração e a vazão final;

- da interação das espécies: a atividade dos ciclos biogeoquímicos depende da interação dos organismos vivos, incluindo a microfauna e a microflora. 


\section{MATERIAL E MÉTODOS}

\subsection{Formulação do Modelo básico de Programação Linear}

A formulação genérica do modelo matemático básico de programação linear (Rodriguez \& Borges, 1999) utilizado para definir o problema de planejamento da colheita florestal é apresentada a seguir:

\subsubsection{Função Objetivo}

A função objetivo foi definida com o propósito de maximizar o valor presente líquido global do empreendimento, ou seja:

$$
\text { Maximizar } \quad V T P=\sum_{i=1}^{N}\left(\sum_{k=1}^{M} D_{i k} X_{i k}\right)
$$

onde:

$V T P=$ valor total do projeto (valor presente líquido);

$N=$ número de talhões ou unidades de gestão (UG);

$M=$ número de prescrições (regimes de manejo);

$D_{i k}=$ valor da prescrição $k$ por unidade de área se implementada no talhão $i$ (valor presente líquido por hectare);

$X_{i k}=$ área da unidade de gestão $i$ designada à prescrição $k$.

O índice $k$ identifica a prescrição de manejo florestal, ou seja, o regime de talhadia simples considerando-se a variação possível da idade mínima e máxima permitidas para o corte em cada rotação, limitadas entre 5 e 7 anos, respectivamente. 
Miragaia et al. (1999), define Unidade de Gestão (UG) como sendo uma área geograficamente contígua e homogênea em termos ecológicos (relevo, solo, material genético) e produtivos (produtividade da floresta).

\subsubsection{Restrições}

a) Restrições de área

A soma das áreas atribuídas às diferentes prescrições dentro das unidades de gestão não pode superar a área disponível nas próprias unidades de gestão.

$$
\sum_{k=1}^{M} X_{i k} \leq A_{i} \quad(i=1,2, \ldots N)
$$

onde:

$A_{i}=$ área total da unidade de gestão

b) Restrições de fluxo de produção não decrescente

Essas expressões matemáticas são necessárias para impor que a produção entre dois anos subseqüentes seja não decrescente, uma vez que a principal meta do empreendedor é a produção periódica de um volume de madeira, para atender uma demanda preestabelecida.

$$
\begin{gathered}
\sum_{i=1}^{N}\left(\sum_{k=1}^{M} v_{i k t} X_{i k}\right)-V T_{t}=0 \quad(t=1,2, \ldots T) \\
V T_{t+1} \geq V T_{t} \quad(t=1,2, \ldots T)
\end{gathered}
$$

onde:

$T=$ número de períodos no horizonte de planejamento.

$v_{i k t}=$ volume de madeira colhida no período $t$ por unidade de área do talhão $i$ se a prescrição $k$ for conduzida.

$V T_{t}=$ volume total de madeira produzido no período $t$. 
Para a construção e implementação desse modelo foram utilizados os dados provenientes de 31 fazendas pertencente a Votorantim Celulose e Papel S/A, localizadas na região do Vale do Paraíba, Estado de São Paulo. Todas as informações referentes a área estudada foram descritas a seguir:

\subsection{Caracterização da área de estudo}

As fazendas estudadas localizam-se nos municípios Santa Branca, Guararema e Monteiro Lobato, Estado de São Paulo.

A região possui uma precipitação média anual de $1.562 \mathrm{~mm}$ (DAEE, 1993). A temperatura máxima média é de $26^{\circ} \mathrm{C}$ e a temperatura mínima média é de $22^{\circ} \mathrm{C}$ (Nascimento \& Pereira, 1988).

Segundo a classificação de Köeppen, a área compreende o tipo climático Cwa, que corresponde ao clima mesotérmico com verões quentes e invernos secos.

A geologia é arqueana, pertencendo ao complexo Paraíba do Sul, que abrange um agrupamento composto por gnaisses bandados, migmatitos, lentes de quartizitos, anfibólitos, mármores e gnaisses granitóides (Brasil, 1983).

Morfologicamente, pertence aos domínios morfo-estruturais - faixas de dobramentos remobilizados, região das escarpas e reversos de serra do mar, cuja topografia em toda a sua extensão, apresenta vales alongados, segmentos de drenagem retilíneos, linhas de cristais e de cumeadas paralelas, relevo com grandes desníveis altimétricos e escarpas. A unidade geomorfológica é o planalto do Paraitinga-Paraibuna, onde o comportamento espacial da rede de drenagem se apresenta fundamentado na organização tectônica da área, com padrão regular a subdendrítico adaptado aos sistemas de falhas e fraturas (Brasil, 1983).

O solo que predomina na região é o Podzólico Vermelho-Amarelo álico $\mathrm{Tb} \mathrm{A}$ moderado textura média/argilosa (FLORIN, 1988). E a vegetação original era do tipo ombrófila densa (Brasil, 1983). 


\subsubsection{Caracterização das fazendas e seus plantios florestais}

As fazendas que foram consideradas neste estudo estão descritas na Tabela 1, bem como suas respectivas áreas, idade e rotação dos plantios. No total, essas fazendas constituem as 35 Unidades de Gestão (UG) consideradas neste trabalho. A área total plantada é de 8.007,80 ha.

Tabela 1. Caracterização das Fazendas e das Unidades de Gestão (UG) com seus respectivos plantios.

\begin{tabular}{|c|c|c|c|c|c|c|}
\hline UG & Fazenda & Gleba & $\begin{array}{c}\text { Área } \\
\text { (ha) }\end{array}$ & $\begin{array}{l}\text { Material } \\
\text { Genético }\end{array}$ & Idade* & Rotação \\
\hline 1 & Angola & Angola & 118,15 & 3 & 0 & 1 \\
\hline 2 & Santo Antônio III & Santo Antônio III & 39,33 & 1 & 5 & 1 \\
\hline 3 & Banco & Banco G1 & 374,60 & 3 & 0 & 1 \\
\hline 4 & Banco & Banco G2 & 261,91 & 3 & 1 & 1 \\
\hline 5 & Barra Bonita & Barra Bonita & 139,00 & 1 & 5 & 1 \\
\hline 6 & Barra Limpa & Barra Limpa & 211,23 & 1 & 5 & 1 \\
\hline 7 & Bela Vista III & Bela Vista III, G1 & 156,13 & 1 & 5 & 1 \\
\hline 8 & Bela Vista III & Bela Vista III, G2 & 86,10 & 2 & 7 & 2 \\
\hline 9 & Santa Branca & Santa Branca & 369,45 & 4 & 3 & 1 \\
\hline 10 & São Carlos & São Carlos & 339,08 & 1 & 3 & 1 \\
\hline 11 & São Joaquim & São Joaquim & 667,09 & 4 & 2 & 1 \\
\hline 12 & São José IV & São José IV & 206,00 & 1 & 2 & 1 \\
\hline 13 & São José V & São José V & 41,07 & 4 & 1 & 1 \\
\hline 14 & Santa Laura & Santa Laura & 104,69 & 1 & 1 & 2 \\
\hline 15 & Santa Luzia & Santa Luzia & 193,10 & 1 & 3 & 1 \\
\hline 16 & Santa Maria & Santa Maria & 473,50 & 4 & 2 & 1 \\
\hline 17 & Morro Azul & Morro Azul & 465,32 & 1 & 5 & 1 \\
\hline 18 & São Pedro II & São Pedro II & 236,10 & 1 & 3 & 1 \\
\hline 19 & Rogemar & Rogemar & 180,11 & 1 & 5 & 1 \\
\hline 20 & Rosa Helena & Rosa Helena G1 & 75,00 & 1 & 4 & 1 \\
\hline 21 & Rosa Helena & Rosa Helena G2 & 82,00 & 1 & 7 & 1 \\
\hline 22 & São Sebastião III & São Sebastião III & 78,98 & 1 & 6 & 1 \\
\hline 23 & São Silvestre & São Silvestre & 145,79 & 1 & 7 & 1 \\
\hline 24 & Taboão & Taboão & 290,04 & 1 & 5 & 1 \\
\hline 25 & Tietê & Tietê & 51,51 & 4 & 1 & 1 \\
\hline 26 & Santo Antônio II & Santo Antônio II & 75,55 & 5 & 0 & 1 \\
\hline 27 & Espirito Santo/Fartura & Espirito Santo/F & 320,12 & 1 & 5 & 1 \\
\hline
\end{tabular}


Tabela 1. Caracterização das Fazendas e das Unidades de Gestão (UG) com seus respectivos plantios.

\begin{tabular}{ccccccc}
\hline UG & Fazenda & Gleba & $\begin{array}{c}\text { Área } \\
\text { (ha) }\end{array}$ & $\begin{array}{c}\text { Material } \\
\text { Genético }\end{array}$ & Idade* $^{\text {Rotação }}$ \\
\hline 28 & Hercília/Mascarenhas & Hercilia/Masc. & 652,67 & 4 & 4 & 1 \\
29 & São Luiz & São Luiz & 159,52 & 1 & 6 & 1 \\
30 & Picapau Amarelo & Pica pau Amarelo & 149,02 & 2 & 5 & 1 \\
31 & Santa Rita II & Santa Rita II & 123,40 & 5 & 1 & 1 \\
32 & Sertãozinho & Sertãozinho G1 & 52,20 & 1 & 4 & 1 \\
33 & Sertãozinho & Sertãozinho G2 & 30,00 & 1 & 6 & 2 \\
34 & Karacy & Karacy G1 a G5 & 800,00 & 4 & 0 & 1 \\
35 & Franco, Pena & Franco, Pena & 260,04 & 4 & 0 & 1 \\
\hline \multicolumn{7}{r}{} \\
\hline
\end{tabular}

* Idade completada na data 01/06/2001

Fonte: Relatório Interno VCP, 2001.

Os dados apresentados a seguir refletem as produtividades dos plantios florestais em cada UG, para a primeira e segunda rotação e para o intervalo de 1 a 9 anos de idade (Tabela 2).

Tabela 2. Produtividade dos plantios em cada Unidade de Gestão (UG)

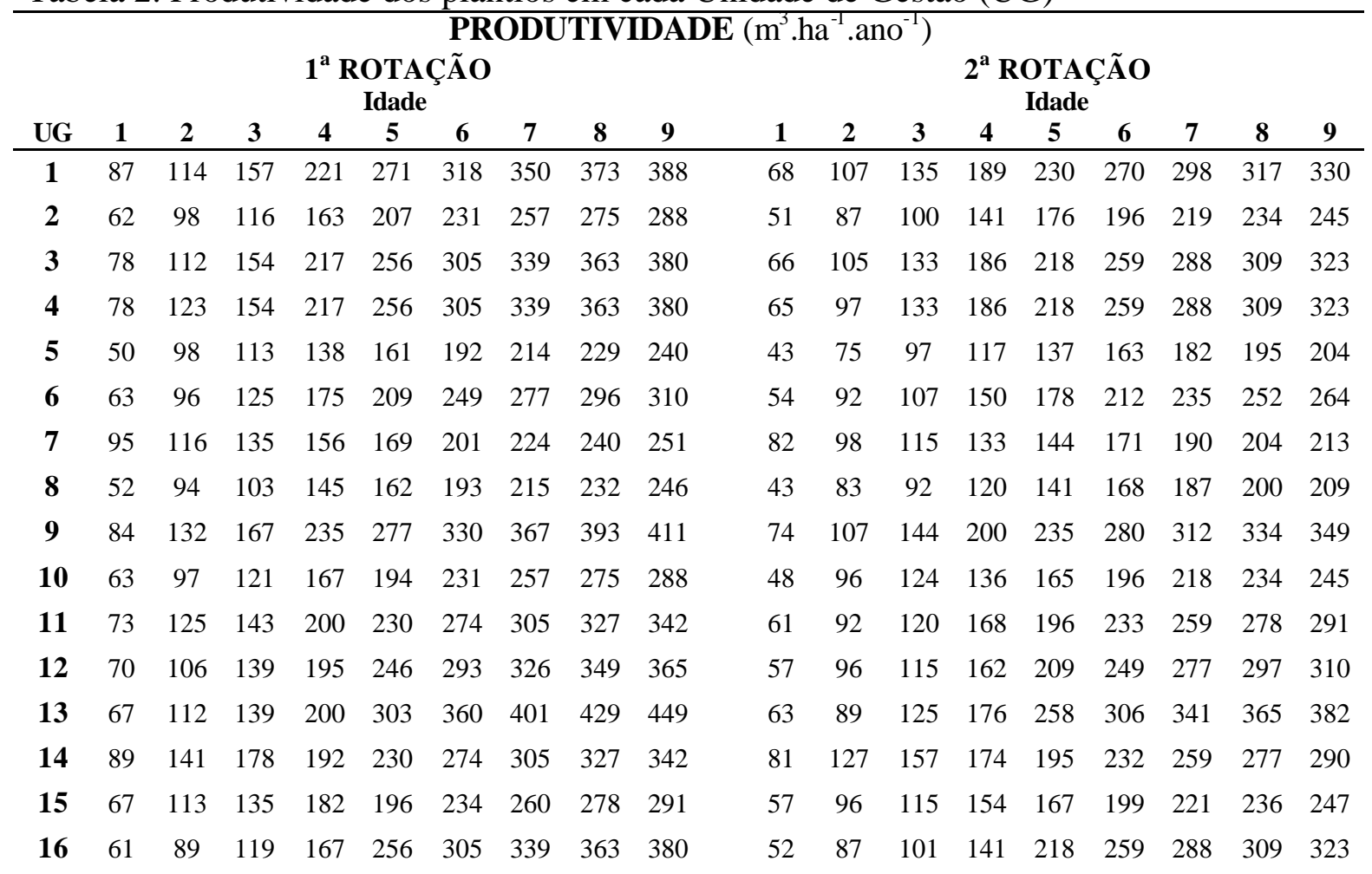


Tabela 2. Produtividade dos plantios em cada Unidade de Gestão (UG)

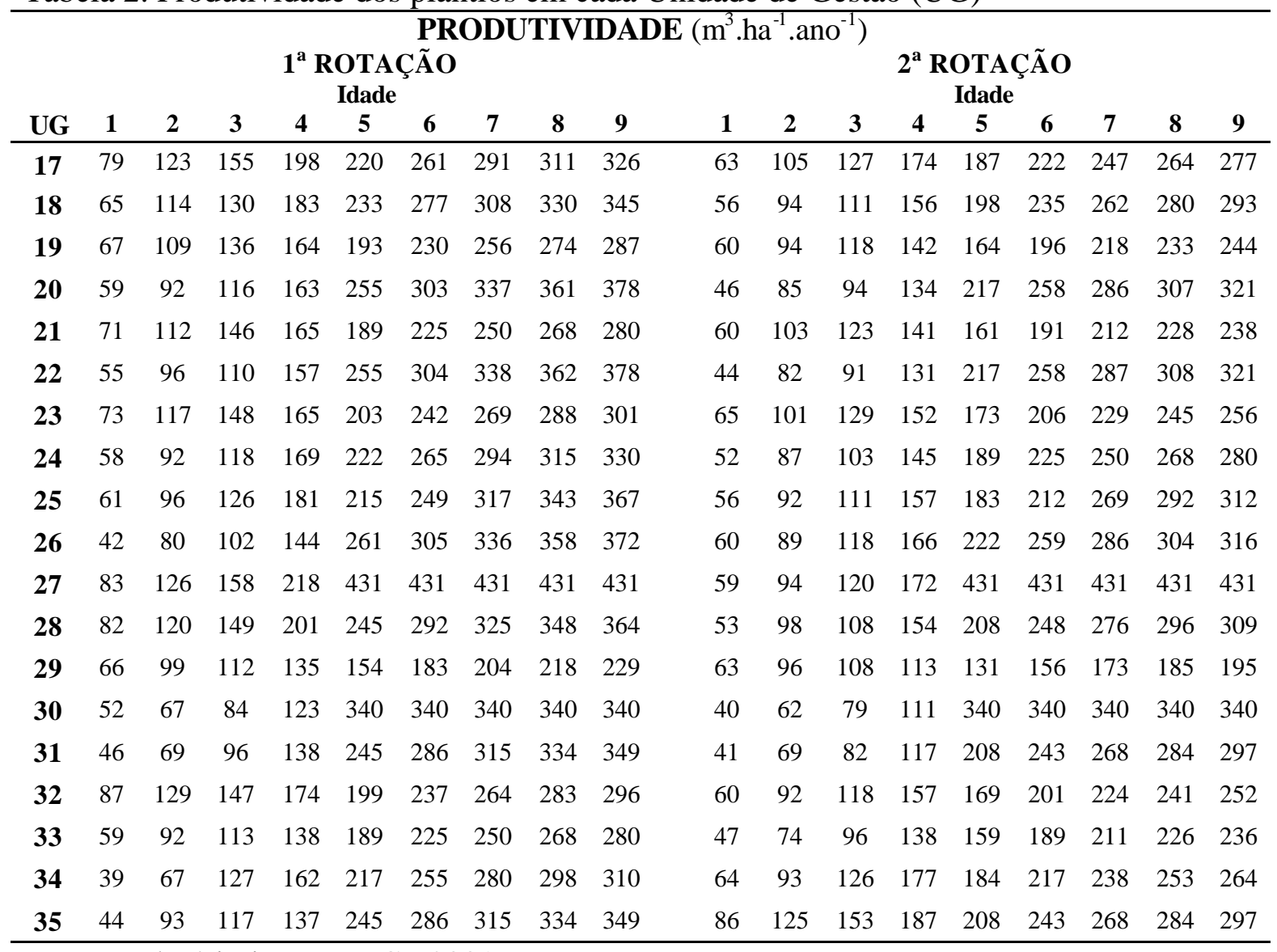

Fonte: Relatório interno VCP 2001

\subsubsection{Fazenda Bela Vista III}

A Fazenda Bela Vista III, localizada no Vale do Paraíba, Município de Santa Branca, Estado de São Paulo, destaca-se em relação às demais pois é nela que se localizam as duas microbacias experimentais de onde foram coletados os dados hidrológicos deste trabalho.

Essa fazenda possui uma área plantada de 241,95 hectares e se encontra entre as coordenadas de $23^{\circ} 25^{\prime}$ de latitude Sul e $45^{\circ} 54^{\prime}$ de longitude Oeste de Greenwich. A altitude varia de $665 \mathrm{~m}$ a $725 \mathrm{~m}$.

A fazenda florestal teve os primeiros plantios de eucaliptos introduzidos em abril de 1987. A espécie utilizada foi o Eucalyptus saligna Smith. 
A fazenda possui duas microbacias hidrográficas experimentais, denominadas A e $B$, e representam bem as principais características topográficas da região. São adjacentes, localizam-se na região central da propriedade e estão sendo monitoradas desde 1987. Os dados de monitoramento dessas microbacias foram extrapolados para todas as fazendas consideradas neste trabalho.

A microbacia A possui uma área de 7,0 ha, sendo 3,3\% ocupada por mata ciliar, com uma declividade média de 19,6\% e apresenta como material de origem a cobertura colúvio/aluvionar Pleistocênico sobre a sericita-xisto. O colúvio, por se tratar de material pré-intemperizado, ocasiona as seguintes características (Ranzini, 1990): topografia mais suave, solos mais profundos, menor gradiente textural entre os horizontes A e B, maior porcentagem de argila floculada que na microbacia $\mathrm{B}$, e maior infiltração de água.

A microbacia B tem uma área de 6,7 ha, dos quais $2,1 \%$ são de mata ciliar, com uma declividade média de $28,9 \%$. Possui o mesmo material de origem da microbacia A, com exceção do seu terço inferior onde não ocorre o recobrimento pleistocênico. Suas encostas íngremes apresentam um gradiente textural acentuado (24,7\% de argila no Horizonte A contra $40.9 \%$ no horizonte B).

Grande parte das informações que caracterizam a área das microbacias é descrita por Ranzini (1990) e Vital (1996).

\subsubsection{Custos das atividades florestais praticados pela empresa}

Os custos médios por hectare de todas as atividades florestais realizadas pela empresa Votorantim Celulose e Papel S/A foram plotadas na Tabela 3 e 4 . A Tabela 3 descreve todas as atividades florestais com seus respectivos custos médios da $1^{\mathrm{a}}$ rotação. A Tabela 4 descreve os custos de manutenção do manejo de brotação ( $2^{\mathrm{a}}$ rotação). Para a composição do custo médio das atividades florestais foram consideradas mão-de-obra, máquinas e insumos. 
Tabela 3. Custo médio anual das atividades florestais ( $1^{\mathrm{a}}$ rotação)

\begin{tabular}{|c|c|c|}
\hline & Atividades & Custo $\left(\mathbf{R} \$ . h a^{-1}\right)$ \\
\hline \multirow{4}{*}{$\begin{array}{c}\text { IMPLANTAÇÃO } \\
\text { Ano } 0\end{array}$} & Limpeza química mecanizada & 94,90 \\
\hline & Preparo do solo mecanizado & 62,50 \\
\hline & Adubação pré-plantio & 179,28 \\
\hline & Plantio & 242,15 \\
\hline \multirow{8}{*}{$\begin{array}{c}\text { MANUTENÇÃO } \\
1^{o} \text { ano }\end{array}$} & Total $(\operatorname{ano} 0)$ & 578,83 \\
\hline & Capina química manual área total I & 139,96 \\
\hline & Capina química manual área total II & 125,11 \\
\hline & Capina química manual coroa & 64,18 \\
\hline & Roçada manual I & 112,50 \\
\hline & Adubação química (3 meses) & 197,69 \\
\hline & Aplicação calcário & 44,82 \\
\hline & Adubação fosfatada & 65,91 \\
\hline \multirow{6}{*}{$\begin{array}{c}\text { MANUTENÇÃO } \\
2^{o} \text { ano }\end{array}$} & Total $\left(1^{\circ}\right.$ ano $)$ & 802,30 \\
\hline & Capina química manual Área Total I & 162,65 \\
\hline & Roçada manual & 11,25 \\
\hline & Combate a formigas & 32,58 \\
\hline & Adubação química (18 meses) & 45,54 \\
\hline & Total $\left(2^{\circ}\right.$ ano $)$ & 252,02 \\
\hline \multirow{4}{*}{$\begin{array}{c}\text { MANUTENÇत्AO } \\
3^{o} \text { ano e } 4^{o} \text { ano }\end{array}$} & Capina química manual Área Total II & 62,56 \\
\hline & Roçada manual I & 11,25 \\
\hline & Combate a formigas & 19,55 \\
\hline & Total $\left(3^{\circ}\right.$ ano e $4^{\circ}$ ano $)$ & 93,36 \\
\hline \multirow{4}{*}{$\begin{array}{c}\text { MANUTENÇ̃ } O \\
5^{\circ} \text { ano e } 6^{\circ} \text { ano }\end{array}$} & Capina química manual Área Total II & 6,26 \\
\hline & Roçada manual II & 7,88 \\
\hline & Combate a formigas & 3,26 \\
\hline & Total $\left(5^{\circ}\right.$ ano e $6^{\circ}$ ano $)$ & 17,39 \\
\hline \multirow{3}{*}{$\begin{array}{c}\text { MANUTENÇÃO } \\
\text { (ano do corte) }\end{array}$} & Roçada pré corte química manual & 96,08 \\
\hline & Combate a formigas & 32,58 \\
\hline & Total (ano do corte) & 128,66 \\
\hline
\end{tabular}

Fonte: Relatório Interno VCP, 2001 
Tabela 4. Custo médio anual da manutenção da brotação ( $2^{\mathrm{a}}$ rotação)

\begin{tabular}{|c|c|c|}
\hline & Atividades & Custo $\left(\mathbf{R} \$ . \mathrm{ha}^{-1}\right)$ \\
\hline \multirow{6}{*}{ 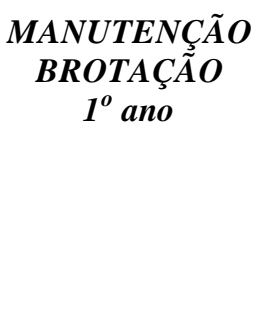 } & Capina química manual área total I & 139,96 \\
\hline & Roçada manual I & 112,50 \\
\hline & Combate à formiga & 52,13 \\
\hline & Total $\left(1^{\circ}\right.$ ano $)$ & 304,59 \\
\hline & Desbrota manual & 225,00 \\
\hline & Capina química manual área total II & 12,51 \\
\hline \multirow{4}{*}{ 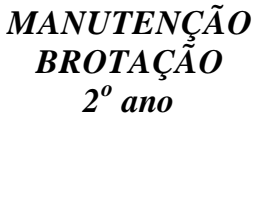 } & Roçada manual I & 11,25 \\
\hline & Combate à formiga & 32,58 \\
\hline & Adubação (18 meses) & 136,80 \\
\hline & Total $\left(2^{\circ}\right.$ ano $)$ & 418,14 \\
\hline \multirow{4}{*}{ 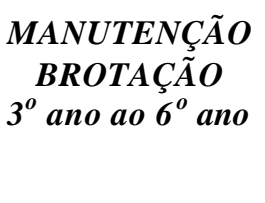 } & Capina química manual área total II & 6,26 \\
\hline & Roçada manual II & 7,88 \\
\hline & Combate à Formiga & 3,26 \\
\hline & Total $\left(3^{\circ}\right.$ ano ao $6^{\circ}$ ano $)$ & 17,39 \\
\hline \multirow[t]{2}{*}{$\begin{array}{c}\text { MANUTENÇÃO } \\
\text { (ano do corte) }\end{array}$} & Combate a formigas & 32,58 \\
\hline & Total (ano do corte) & 32,58 \\
\hline
\end{tabular}

Fonte: Relatório Interno VCP, 2001

Para o cálculo do "custo da madeira posto fábrica" considerou-se:

a) custo de colheita (Harvester + Forwarder) $=2.745,00 \mathrm{R} \$ . \mathrm{ha}^{-1}$;

b) volume de madeira em cada UG (Unidade de Gestão) entre os 5 e 9 anos $\left(\mathrm{m}^{3} \cdot \mathrm{ha}^{-1}\right)$;

c) custo do frete, considerando a distância de cada fazenda até a fábrica $\left(\mathrm{R} \$ \cdot \mathrm{m}^{-3}\right)$.

Como resultado obteve-se um valor de "Custo de madeira posto fábrica" para cada UG em cada ano possível de se realizar o corte (5 aos 9 anos). 


\subsection{Construção do modelo básico de programação linear e suas variações}

\subsubsection{Cálculo dos coeficientes da função objetivo e geração das alternativas de manejo}

O cálculo dos coeficientes da função objetivo considera o Valor Presente de cada regime de manejo, e foi baseado nos custos médios das atividades florestais previstas para as fazendas estudadas (Tabelas 3 e 4), no Valor Esperado da Terra (VET) calculado para cada fazenda e no preço da madeira posto fábrica.

O Valor Esperado da Terra (VET) é a somatória do valor presente das receitas líquidas obtidas periodicamente no final de cada ciclo de produção florestal que se repete perpetuamente. Esse artifício torna os valores presentes, de quaisquer que sejam os regimes de manejo, comparáveis, mesmo apresentando fluxos de caixa com períodos de duração diferentes (Rodriguez, 1991).

$$
V E T_{i}=\frac{R L_{n_{i}}}{\left[(1+i)^{n_{i}}-1\right]}
$$

onde:

$V E T_{i}=$ valor esperado da terra da unidade de manejo $i$;

$R l_{n i}=$ receita líquida no ano $n_{i}$

$n_{i}=$ último ano do fluxo de caixa do melhor regime de manejo florestal recomendado para a unidade de manejo $i$.

Para o cálculo dos coeficientes da função objetivo e a para a geração das alternativas de manejo foi utilizado um programa especialmente desenvolvido para esse fim. A função básica desse programa, denominado Gerador é: (i) gerar regimes alternativos para o manejo de cada unidade de gestão; (ii) avaliar economicamente cada regime gerado; e (iii) formatar os dados para que o gestor possa avaliar os resultados ou utilizá-los em outros módulos que dêem continuidade a sua análise (Nobre e Rodriguez, 2001). 
O programa Gerador obedece uma certa sequiência de etapas para definir todas as alternativas de manejo por talhadia às quais um conjunto de Unidades de Gestão (UG) estão sujeitas, sendo que o número de regimes de talhadia possíveis varia em função do número mínimo e máximo de rotações permitidas (Rmín e Rmáx), e do horizonte de tempo considerado na análise $(h)$.

$1^{a}$ Etapa: Definida a duração do horizonte de planejamento $(h)$; o número mínimo e máximo de rotações por ciclo (Rmín e Rmáx); e a idade mínima e máxima de corte (Imín e Imáx), o programa gera todas as sequiências possíveis de manejo, combinando condução $(\mathrm{C})$ e reforma (R).

$2^{a}$ Etapa: Após a definição das informações básicas sobre as unidades de gestão (idade $(i)$, rotação $(r)$ no ano 0 , tabela de produção, custos específicos de manejo e colheita, preços do produto florestal) o programa gera os regimes de manejo possíveis e cria os respectivos fluxos de receitas e custos.

$3^{a}$ Etapa: Definida uma taxa de juros, e com os fluxos de caixa gerados na etapa anterior, o programa seleciona o melhor ciclo e calcula o respectivo VET. Esse VET é utilizado para a uniformizar financeiramente os fluxos de caixa.

$4^{a}$ Etapa: Com os fluxos de caixa uniformizados, o programa calcula o valor presente líquido (VPL) de cada fluxo de caixa resultante.

Para a perfeita execução do método Gerador, este necessita ser alimentado com os seguintes dados:

a) Unidades de Gestão (UG), idade da floresta, área, material genético, rotação (Tabela 1);

b) Produção volumétrica em cada UG nos possíveis anos de corte (Tabela 2);

c) Custos médios anuais por hectare de todas as atividades florestais (Tabela 3 e 4);

d) Custos de colheita por unidade de volume.

Além dos dados anteriormente citados, o programa Gerador exige a definição de alguns parâmetros descritos na Tabela 5. 
Tabela 5. Parâmetros exigidos pelo programa Gerador.

\begin{tabular}{lc}
\hline Parâmetros & Definição \\
\hline Idade mínima de corte & 5 anos \\
Idade máxima de corte & 7 anos \\
Número mínimo de rotações por ciclo & 1 rotação \\
Número máximo de rotações por ciclo & 2 rotações \\
Taxa de rentabilidade dos investimentos & $10 \%$ \\
Preço de venda da madeira por $\mathrm{m}^{3}$ sólido entregue na fábrica & $\mathrm{R} \$ 30,00$ \\
Horizonte de planejamento & 14 anos \\
\hline
\end{tabular}

Com os parâmetros determinados, o programa de geração de regimes resultou em 1750 regimes de manejo com seus respectivos valores presentes. $\mathrm{O}$ resultado pode ser analisado em telas como a exibida na Figura 1.

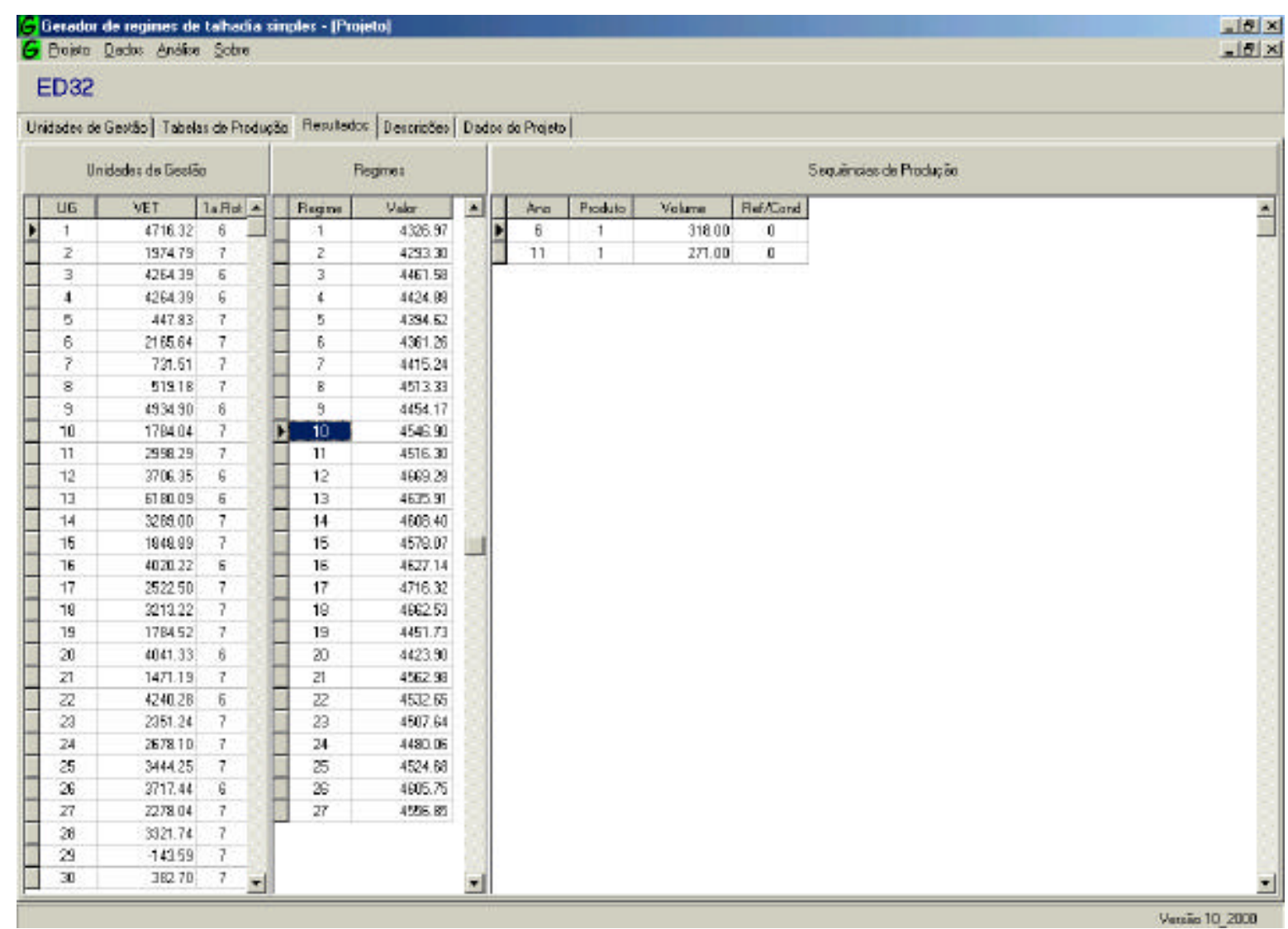

Figura 1 - Tela de resultados do programa Gerador. 
Na Figura 1 à janela a esquerda mostra o Valor Esperado da Terra (VET) e a duração do ciclo ótimo para cada unidade de manejo. A tela central exibe o Valor Presente Líquido (VPL) de todos os regimes de manejo possíveis de serem implementados para a unidade de manejo ativa na tela da esquerda (no caso UG $=1$ ). A janela à direita mostra quando ocorrerão as intervenções de colheita do regime em destaque na tela central (no caso regime $=10$ ).

Com todos os dados gerados pelo programa Gerador, foi possível montar o modelo básico de programação linear contendo 1750 variáveis, 35 restrições de área e 14 restrições de produção. O problema de programação linear foi submetido ao programa Cplex, específico para solução de problemas de Programação Linear de grande porte.

Parte da estrutura do modelo é apresentado no Quadro 1 a seguir. 


\section{FUNÇÃO OBJETIVO}

\section{Max VTP :}

$4326.97 \mathrm{U} 1 \mathrm{R} 1+4293.3 \mathrm{U} 1 \mathrm{R} 2+4461.58 \mathrm{U} 1 \mathrm{R} 3+4424.88 \mathrm{U} 1 \mathrm{R} 4+4394.62 \mathrm{U} 1 \mathrm{R} 5$ $+4361.26 \mathrm{U} 1 \mathrm{R} 6+4415.24 \mathrm{U} 1 \mathrm{R} 7+4513.33 \mathrm{U} 1 \mathrm{R} 8+4454.17 \mathrm{U} 1 \mathrm{R} 9+4546.9 \mathrm{U} 1 \mathrm{R} 10$ $4516.3 \mathrm{U} 1 \mathrm{R} 11+4669.28 \mathrm{U} 1 \mathrm{R} 12+4635.91 \mathrm{U} 1 \mathrm{R} 13+4608.4 \mathrm{U} 1 \mathrm{R} 14+4578.07 \mathrm{U} 1 \mathrm{R} 15$ $+4627.14 \mathrm{U1R} 16+\ldots+3345.74 \mathrm{U} 36 \mathrm{R} 12+3323.85 \mathrm{U} 36 \mathrm{R} 13+3323.83 \mathrm{U} 36 \mathrm{R} 14+$ $3303.93 \mathrm{U} 36 \mathrm{R} 15+3342.95 \mathrm{U} 36 \mathrm{R} 16+3445.49 \mathrm{U} 36 \mathrm{R} 17+3425.21 \mathrm{U} 36 \mathrm{R} 18+3193.38$ $\mathrm{U} 36 \mathrm{R} 19+3177.02 \mathrm{U} 36 \mathrm{R} 20+3310.19 \mathrm{U} 36 \mathrm{R} 21+3290.29 \mathrm{U} 36 \mathrm{R} 22+3290.27 \mathrm{U} 36 \mathrm{R} 23+$ $3272.18 \mathrm{U} 36 \mathrm{R} 24+3307.65 \mathrm{U} 36 \mathrm{R} 25+3400.88 \mathrm{U} 36 \mathrm{R} 26+3382.43 \mathrm{U} 36 \mathrm{R} 27$

\section{RESTRIÇÃO : Área}

\section{Sujeito a}

\section{UG1 :}

$\mathrm{U} 1 \mathrm{R} 1+\mathrm{U} 1 \mathrm{R} 2+\mathrm{U} 1 \mathrm{R} 3+\mathrm{U} 1 \mathrm{R} 4+\mathrm{U} 1 \mathrm{R} 5+\mathrm{U} 1 \mathrm{R} 6+\mathrm{U} 1 \mathrm{R} 7+\mathrm{U} 1 \mathrm{R} 8+\mathrm{U} 1 \mathrm{R} 9+\mathrm{U} 1 \mathrm{R} 10$

$+\mathrm{U} 1 \mathrm{R} 11+\mathrm{U} 1 \mathrm{R} 12+\mathrm{U} 1 \mathrm{R} 13+\mathrm{U} 1 \mathrm{R} 14+\mathrm{U} 1 \mathrm{R} 15+\mathrm{U} 1 \mathrm{R} 16+\mathrm{U} 1 \mathrm{R} 17+\mathrm{U} 1 \mathrm{R} 18+\mathrm{U} 1 \mathrm{R} 19$

$+\mathrm{U} 1 \mathrm{R} 20+\mathrm{U} 1 \mathrm{R} 21+\mathrm{U} 1 \mathrm{R} 22+\mathrm{U} 1 \mathrm{R} 23+\mathrm{U} 1 \mathrm{R} 24+\mathrm{U} 1 \mathrm{R} 25+\mathrm{U} 1 \mathrm{R} 26+\mathrm{U} 1 \mathrm{R} 27<=118.15$

UG36:

$\mathrm{U} 36 \mathrm{R} 1+\mathrm{U} 36 \mathrm{R} 2+\mathrm{U} 36 \mathrm{R} 3+\mathrm{U} 36 \mathrm{R} 4+\mathrm{U} 36 \mathrm{R} 5+\mathrm{U} 36 \mathrm{R} 6+\mathrm{U} 36 \mathrm{R} 7+\mathrm{U} 36 \mathrm{R} 8+\mathrm{U} 36 \mathrm{R} 9$

$+\mathrm{U} 36 \mathrm{R} 10+\mathrm{U} 36 \mathrm{R} 11+\mathrm{U} 36 \mathrm{R} 12+\mathrm{U} 36 \mathrm{R} 13+\mathrm{U} 36 \mathrm{R} 14+\mathrm{U} 36 \mathrm{R} 15+\mathrm{U} 36 \mathrm{R} 16+\mathrm{U} 36 \mathrm{R} 17$

$+\mathrm{U} 36 \mathrm{R} 18+\mathrm{U} 36 \mathrm{R} 19+\mathrm{U} 36 \mathrm{R} 20+\mathrm{U} 36 \mathrm{R} 21+\mathrm{U} 36 \mathrm{R} 22+\mathrm{U} 36 \mathrm{R} 23+\mathrm{U} 36 \mathrm{R} 24+\mathrm{U} 36 \mathrm{R} 25$

$+\mathrm{U} 36 \mathrm{R} 26+\mathrm{U} 36 \mathrm{R} 27<=260.04$

\section{RESTRIÇÃo: Produção}

P1 :

$231 \mathrm{U} 2 \mathrm{R} 1+231 \mathrm{U} 2 \mathrm{R} 2+231 \mathrm{U} 2 \mathrm{R} 3+231 \mathrm{U} 2 \mathrm{R} 4+231 \mathrm{U} 2 \mathrm{R} 5+231 \mathrm{U} 2 \mathrm{R} 6+231$

$\mathrm{U} 2 \mathrm{R} 7+231 \mathrm{U} 2 \mathrm{R} 8+231 \mathrm{U} 2 \mathrm{R} 9+231 \mathrm{U} 2 \mathrm{R} 10+231 \mathrm{U} 2 \mathrm{R} 11+231 \mathrm{U} 2 \mathrm{R} 12+231$

$\mathrm{U} 2 \mathrm{R} 13+231 \mathrm{U} 2 \mathrm{R} 14+231 \mathrm{U} 2 \mathrm{R} 15+\ldots+139 \mathrm{U} 34 \mathrm{R} 16+139 \mathrm{U} 34 \mathrm{R} 17+139 \mathrm{U} 34 \mathrm{R} 18+$

$139 \mathrm{U} 34 \mathrm{R} 19+139 \mathrm{U} 34 \mathrm{R} 20+139 \mathrm{U} 34 \mathrm{R} 21+139 \mathrm{U} 34 \mathrm{R} 22+139 \mathrm{U} 34 \mathrm{R} 23+139 \mathrm{U} 34 \mathrm{R} 24$

$-\operatorname{PROD} 1=0$

P14:

$350 \mathrm{U} 1 \mathrm{R} 23$ + $350 \mathrm{U} 1 \mathrm{R} 24+298 \mathrm{U} 1 \mathrm{R} 27+257 \mathrm{U} 2 \mathrm{R} 14+257 \mathrm{U} 2 \mathrm{R} 15+219 \mathrm{U} 2 \mathrm{R} 18$

$+231 \mathrm{U} 2 \mathrm{R} 21+196 \mathrm{U} 2 \mathrm{R} 23+257 \mathrm{U} 2 \mathrm{R} 35+257 \mathrm{U} 2 \mathrm{R} 36+231 \mathrm{U} 2 \mathrm{R} 39+257 \mathrm{U} 2 \mathrm{R} 44$

$+257 \mathrm{U} 2 \mathrm{R} 45+219 \mathrm{U} 2 \mathrm{R} 48+231 \mathrm{U} 2 \mathrm{R} 51+\ldots+146 \mathrm{U} 34 \mathrm{R} 36+139 \mathrm{U} 34 \mathrm{R} 38+123$

$\mathrm{U} 34 \mathrm{R} 40+106 \mathrm{U} 34 \mathrm{R} 42+280 \mathrm{U} 35 \mathrm{R} 23+280 \mathrm{U} 35 \mathrm{R} 24+238 \mathrm{U} 35 \mathrm{R} 27+315 \mathrm{U} 36 \mathrm{R} 23+$

315 U36R24 + 268 U36R27 - PROD14 $=0$

ORD1×2: PROD1 - PROD2 < 0

ORD13×14: PROD13 - PROD14<0

Quadro 1 - Estrutura do modelo básico de programação linear 


\subsubsection{Montagem da restrição hidrológica}

A restrição hidrológica utilizada para complementar o modelo básico de programação linear foi montada de três formas distintas, o que consequentemente gerou três modelos diferentes que foram comparados e analisados.

Baseado em Lima \& Zakia (1998), o indicador hidrológicos escolhidos para a construção da restrição hidrológica foi o deflúvio, cuja categoria de impacto é a alteração do regime de vazão e a atividade causadora é a silvicultura intensiva e o desmatamento.

As três variantes da restrição hidrológica estão genericamente descritas a seguir:

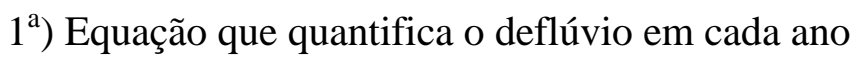

$$
\sum_{i=1}^{N}\left(\sum_{k=1}^{M} q_{i k t} X_{i k}\right)-Q_{t}=0 \quad(t=1,2, \ldots T)
$$

$2^{\mathrm{a}}$ ) Equações que tornam o deflúvio não crescente ao longo do horizonte de planejamento.

$$
\begin{gathered}
\sum_{i=1}^{N}\left(\sum_{k=1}^{M} q_{i k t} X_{i k}\right)-Q_{t}=0 \quad(t=1,2, \ldots T) \\
Q_{t+1} \leq Q_{t} \quad(t=1,2, \ldots T)
\end{gathered}
$$

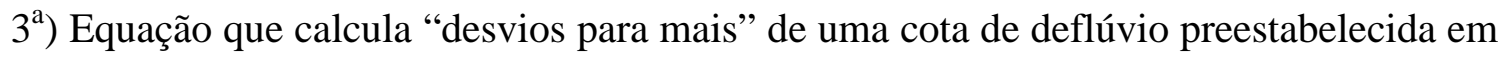
todos os anos do horizonte de planejamento.

$$
\sum_{i=1}^{N}\left(\sum_{k=1}^{M} q_{i k t} X_{i k}\right)-D m a_{t}=\operatorname{QMax}_{t} \quad(t=1,2, \ldots T)
$$

onde:

$q_{i k t}=$ deflúvio por unidade de área no talhão $i$ no período $t$ se manejado através da prescrição $k$;

$Q_{t}=$ deflúvio no período $t$;

$\operatorname{MMax}_{t}=$ deflúvio máximo permitido no período $t$;

$D m a_{t}=$ desvio para mais de uma cota de deflúvio preestabelecida. 
A terceira variante da restrição hidrológica (Equação 9) implica em uma pequena alteração na função objetivo, como demostrado a seguir:

$$
\text { Maximizar } \quad V T P=\sum_{i=1}^{N}\left(\sum_{k=1}^{M} D_{i k} X_{i k}\right)-P D m a_{t} \quad(t=1,2, \ldots T)
$$

Isso ocorre porque a intenção é minimizar os desvios da cota de deflúvio preestabelecida (cota limite), sendo necessário aplicar penalidades ao VTP caso ocorram estes desvios. Essas penalidades farão com que estes desvios sejam os menores possíveis. O valor escolhido para a penalidade foi de $10.000(\mathrm{P}=10.000)$.

A finalidade de encontrar uma cota limite para o deflúvio é tentar simular um cenário onde exista nesta mesma área de estudo uma cobertura de floresta nativa, e a partir desta situação, encontrar um valor de deflúvio máximo que esta floresta possa produzir.

Porém devido a dificuldade de encontrar este valor foi feita a seguinte pressuposição: o deflúvio representado pela floresta de Eucaliptus saligna nas microbacias estudadas quando essa se encontra com quatro anos de idade, eqüivale ao deflúvio produzido quando a área se encontra coberta com floresta nativa. De acordo com Lima ${ }^{1}$, a pressuposição está adequada.

Utilizou-se então, o valor do deflúvio da floresta de eucalipto das microbacias A e B com 4 anos de idade $\left(368,38 \mathrm{~m}^{3}\right.$ de água por ha) multiplicado pela área total do estudo 8.518 ha. Assim, adotou-se 3.131.263,89 $\mathrm{m}^{3}$ de água por ano como sendo um valor máximo permitido para as vazões anuais que ocorrem na área. A partir desta cota preestabelecida a terceira variante da restrição hidrológica (Equação 9) irá computar os desvios para mais quando a mesma for superada.

Finalmente, para a montagem da restrições hidrológica e suas variantes, calculou-se os coeficientes técnicos do deflúvio como demonstrado a seguir.

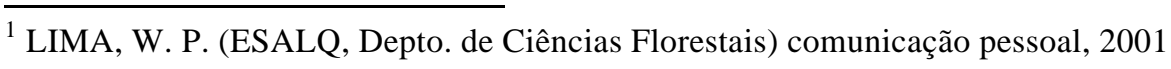




\subsubsection{Cálculo dos coeficientes técnicos do deflúvio}

No cálculo dos coeficientes técnicos hidrológicos, utilizou-se os dados históricos de precipitação e deflúvio, provenientes das duas microbacias experimentais da Fazenda Bela Vista III. Nesse cálculo foram considerados os dados hidrológicos coletados no período de junho de 1987 a maio de 1995. Esse período corresponde ao crescimento do Eucaliptus saligna, desde o seu plantio nas microbacias, até um ano após o corte realizado aos sete anos de idade.

Para a definição dos coeficientes técnicos do deflúvio foram considerados os valores totais de deflúvio $\left(\mathrm{m}^{3} \cdot \mathrm{ha}^{-1}\right)$ dos 4 meses de maior precipitação anual no período estudado.

A preocupação com o período mais chuvoso se justifica pelo fato de estarem restritos a esse período os maiores impactos em termos de perda de solo por erosão laminar e de fertilidade de solo por carreamento de nutrientes. A pressuposição é manter suficiente cobertura vegetal na área estudada de tal forma que nos meses mais chuvosos do ano a parte significativa da água que seria escoada para a microbacia seja evapotranspirada e/ou infiltrada no solo, permitindo dessa forma um maior controle sobre o deflúvio máximo na microbacia.

A escolha do período com quatro meses mais chuvosos tem como base uma análise de regressão que procurou estabelecer a melhor relação "cobertura vegetal (medida pelo volume de madeira em pé)" versus "deflúvio na microbacia para diferentes períodos de maior precipitação". Foram estudados períodos de um, dois, três e quatro meses para definir o período mais chuvosos e estabelecer esta relação.

A Tabela 6 apresenta dados de precipitação $(\mathrm{mm})$ e deflúvio $\left(\mathrm{m}^{3} \cdot \mathrm{ha}^{-1}\right)$ para os 4 meses de maior precipitação em cada ano nas microbacias. 
Tabela 6. Dados de precipitação e deflúvio nos quatro meses mais chuvosos dos anos de 1987 a 1995.

\begin{tabular}{|c|c|c|c|c|c|c|c|}
\hline Mês & $\begin{array}{c}\text { Precip. } \\
(\mathbf{m m})\end{array}$ & $\begin{array}{c}\text { Deflúvio A } \\
\left(\mathbf{m}^{3} \cdot \mathbf{h a}^{-1}\right)\end{array}$ & $\begin{array}{c}\text { Deflúvio B B } \\
\left(\mathbf{m}^{3} \cdot \mathbf{h a}^{-1}\right)\end{array}$ & Mês & $\begin{array}{c}\text { Precip. } \\
(\mathbf{m m})\end{array}$ & $\begin{array}{c}\text { Deflúvio A } \\
\left(\mathrm{m}^{3} \cdot \mathrm{ha}^{-1}\right)\end{array}$ & $\begin{array}{r}\text { Deflúvio B } \\
\left(\mathrm{m}^{3} \cdot \mathrm{ha}^{-1}\right)\end{array}$ \\
\hline $\mathrm{dez} / 87$ & 155,50 & 212,00 & 339,50 & Out/91 & 132,70 & 91,80 & 39,80 \\
\hline $\mathrm{jan} / 88$ & 374,80 & 344,80 & 344,80 & Dez/91 & 208,10 & 100,40 & 52,30 \\
\hline $\mathrm{fev} / 88$ & 295,00 & 449,80 & 532,50 & Fev/92 & 164,40 & 26,60 & 49,90 \\
\hline $\mathrm{mai} / 88$ & 169,30 & 348,60 & 608,60 & Mar/92 & 150,20 & 32,50 & 63,20 \\
\hline Total & 994,60 & 1355,20 & 1825,40 & Total & 655,40 & 251,30 & 205,20 \\
\hline $\mathrm{dez} / 88$ & 134,60 & 236,80 & 550,00 & $\mathrm{dez} / 92$ & 173,00 & 27,50 & 53,60 \\
\hline $\mathrm{jan} / 89$ & 205,20 & 256,20 & 424,00 & $\mathrm{jan} / 93$ & 233,00 & 26,90 & 44,30 \\
\hline $\mathrm{fev} / 89$ & 246,00 & 261,20 & 394,80 & fev/93 & 181,60 & 31,60 & 49,60 \\
\hline $\mathrm{mar} / 89$ & 125,20 & 140,10 & 400,30 & $\mathrm{mar} / 93$ & 134,50 & 24,00 & 42,70 \\
\hline Total & 711,00 & 894,30 & 1769,10 & Total & 722,10 & 110,00 & 190,20 \\
\hline $\mathrm{dez} / 89$ & 178,80 & 107,00 & 153,80 & set/93 & 183,90 & 7,57 & 58,27 \\
\hline $\mathrm{jan} / 90$ & 206,70 & 134,30 & 161,60 & $\mathrm{dez} / 93$ & 129,90 & 3,29 & 52,62 \\
\hline fev/90 & 190,50 & 112,40 & 156,10 & fev/94 & 172,40 & 4,51 & 65,25 \\
\hline $\mathrm{mar} / 90$ & 170,00 & 112,80 & 139,20 & mar/94 & 162,00 & 3,84 & 36,66 \\
\hline Total & 746,00 & 466,50 & 610,70 & Total & 648,20 & 19,21 & 212,80 \\
\hline $\mathrm{jan} / 91$ & 359,70 & 178,90 & 256,10 & $\mathrm{dez} / 94$ & 159,80 & 96,42 & - \\
\hline fev/91 & 202,60 & 137,80 & 101,00 & $\mathrm{jan} / 95$ & 490,00 & 688,56 & - \\
\hline $\mathrm{mar} / 91$ & 342,90 & 134,00 & 109,90 & fev/95 & 181,30 & 82,89 & - \\
\hline $\mathrm{abr} / 91$ & 182,70 & 98,30 & 103,10 & mar/95 & 138,70 & 45,40 & - \\
\hline Total & 1087,90 & 549,00 & 570,10 & & 969,80 & 913,27 & - \\
\hline
\end{tabular}

Os dados totais de deflúvio das microbacias A e B e os dados do volume de madeira da floresta nas microbacias referentes ao mesmo período foram submetidos a uma regressão linear simples para ajustar a versão linearizada do seguinte modelo:

$$
\begin{aligned}
Q & =\alpha \cdot \mathrm{e}^{\beta . V} \\
\ln Q & =\ln \alpha+\beta \cdot V \quad \text { (versão linearizada) }
\end{aligned}
$$

onde:

$Q=\operatorname{deflúvio~}\left(\mathrm{m}^{3} \cdot \mathrm{ha}^{-1}\right)$

$V=$ volume de madeira $\left(\mathrm{m}^{3} \cdot \mathrm{ha}^{-1}\right)$

$\ln =$ logaritmo neperiano

Esse modelo foi selecionado pois permite expressar a relação esperada entre as variáveis estudadas. Espera-se um valor negativo para o parâmetro $\beta$ e neste caso $\alpha$ torna-se o valor assintótico do deflúvio quando a cobertura vegetal for nula $(\mathrm{V}=0)$. 
Sabe-se que além da cobertura florestal (volume de madeira), vários são os aspectos que influenciam as alterações do deflúvio em uma microbacia, tais como (Tucci, 1998):

- diferença de estado de umidade do solo;

- climatologia sazonal: a distribuição da precipitação ao longo do ano e sua intensidade, permitem estabelecer se existirá disponibilidade de água para evapotranspirar.

- diferenças de elevação: a elevação afeta a evaporação pelas características de incidência solar e velocidade do vento.

- profundidade e declividade do solo: influenciam no processo de infiltração.

- grau de alteração do solo devido ao método de colheita: afeta as condições do solo, resultando em maior ou menor escoamento superficial.

- a localização e o tamanho da área cortada: a área cortada e a localização da mesma em relação à seção principal (vertedor) da microbacia influenciam o escoamento.

Entretanto, para o nível de generalização assumido neste trabalho, espera-se com o volume de madeira na floresta explicar adequadamente o deflúvio em todas as Unidades de Gestão estudadas. 
Os dados de deflúvio $\left(\mathrm{m}^{3} \cdot \mathrm{ha}^{-1}\right)$ e volume de madeira $\left(\mathrm{m}^{3} \cdot \mathrm{ha}^{-1}\right)$ utilizados para realizar a regressão linear estão descritos na Tabela 7.

Tabela 7. Valores considerados na regressão linear.

\begin{tabular}{ccc}
\hline $\begin{array}{c}\text { Deflúvio (Q) } \\
\text { Microbacia A e B } \\
\left(\mathbf{m 3 . h a}^{-1}\right)\end{array}$ & Idade & $\begin{array}{c}\text { Volume } \\
\text { madeira }^{-1} \\
\left(\mathbf{m 3 . h a} \mathbf{~}^{-}\right.\end{array}$ \\
\hline 1355,20 & 1 & 95,20 \\
1825,40 & 1 & 95,20 \\
894,30 & 2 & 115,50 \\
1769,10 & 2 & 115,50 \\
466,50 & 3 & 135,80 \\
610,70 & 3 & 135,80 \\
549,00 & 4 & 156,10 \\
570,10 & 4 & 156,10 \\
251,30 & 5 & 169,00 \\
205,20 & 5 & 169,00 \\
110,00 & 6 & 201,00 \\
190,20 & 6 & 201,00 \\
19,21 & 7 & 224,00 \\
212,80 & 7 & 224,00 \\
913,27 & 1 & 81,80 \\
\hline
\end{tabular}

Como resultado do ajuste obteve-se os seguintes valores:

$$
\mathrm{R}^{2}=0,7669 \quad \alpha=9,4405471 \quad \beta=-0,022622814
$$

A Tabela 8 e a Figura 2, ilustram os valores observados e os valores calculados pelo ajuste do modelo utilizando os dados do deflúvio e volumes de madeira das microbacias A e B. Observa-se na Figura 2 que conforme aumenta o volume de madeira em pé na floresta o deflúvio decresce de maneira exponencial. 
Tabela 8. Deflúvio observado e deflúvio calculado resultante do ajuste do modelo.

\begin{tabular}{ccc}
\hline $\begin{array}{c}\text { Volume } \\
\text { Madeira } \\
\text { (m3/ha) }\end{array}$ & $\begin{array}{c}\text { Deflúvio (Q) } \\
\text { Observado } \\
\text { (m3/ha) }\end{array}$ & $\begin{array}{c}\text { Deflúvio (Q) } \\
\text { Calculado } \\
\text { (m3/ha) }\end{array}$ \\
\hline 81,80 & 913,27 & 1978,32 \\
95,20 & 1355,20 & 1460,97 \\
95,20 & 1825,40 & 1460,97 \\
115,50 & 894,30 & 922,98 \\
115,50 & 1769,10 & 922,98 \\
135,80 & 466,50 & 583,11 \\
135,80 & 610,70 & 583,11 \\
156,10 & 549,00 & 368,38 \\
156,10 & 570,10 & 368,38 \\
169,00 & 251,30 & 275,14 \\
169,00 & 205,20 & 275,14 \\
201,00 & 110,00 & 133,40 \\
201,00 & 190,20 & 133,40 \\
224,00 & 19,21 & 79,28 \\
224,00 & 212,80 & 79,28 \\
\hline
\end{tabular}

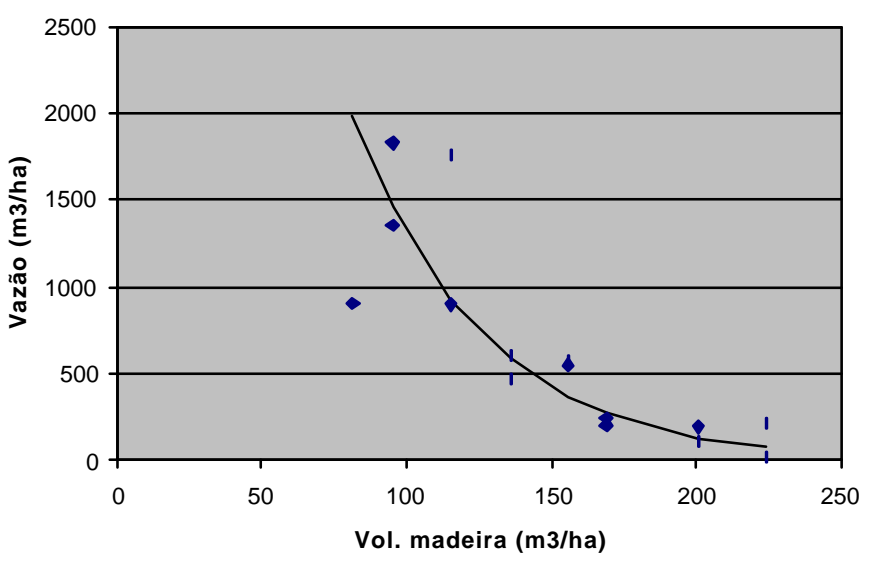

- Q Observada (m3/ha) — Q Calculada (m3/ha)

Figura 2 - Deflúvio observado e deflúvio calculado resultante do ajuste do modelo.

Com o modelo ajustado, realizou-se a extrapolação dos dados, ou seja, o cálculo dos coeficientes técnicos hidrológicos para as demais Unidades de Gestão (UG), utilizando os dados de volume de madeira descritos na Tabela 2. 


\subsection{Estratégias de otimização.}

A estrutura matemática dos três modelos estudados estão representados no Quadro 2.

\begin{tabular}{|c|c|c|}
\hline Modelo 1 (M1) & Modelo 2 (M2) & Modelo 3 (M3) \\
\hline $\operatorname{Max} \quad V T P=\sum_{i=1}^{N}\left(\sum_{k=1}^{M} D_{i k} X_{i k}\right)$ & $\begin{array}{c}\operatorname{Max} \\
V T P=\sum_{i=1}^{N}\left(\sum_{k=1}^{M} D_{i k} X_{i k}\right)\end{array}$ & $V T P=\sum_{i=1}^{N}\left(\sum_{k=1}^{M} D_{i k} X_{i k}\right)-P D m a_{t}$ \\
\hline $\begin{array}{l}\text { Sujeito a: } \\
\qquad \sum_{k=1}^{M} X_{i k} \leq A_{i}\end{array}$ & $\begin{array}{l}\text { Sujeito a: } \\
\qquad \sum_{k=1}^{M} X_{i k} \leq A_{i}\end{array}$ & $\begin{array}{l}\text { Sujeito a: } \\
\qquad \sum_{k=1}^{M} X_{i k} \leq A_{i}\end{array}$ \\
\hline $\begin{array}{c}\sum_{i=1}^{N}\left(\sum_{k=1}^{M} v_{i k t} X_{i k}\right)-V T_{t}=0 \\
V T_{t+1} \geq V T_{t} \\
\sum_{i=1}^{N}\left(\sum_{k=1}^{M} q_{i k t} X_{i k}\right)-Q_{t}=0\end{array}$ & $\begin{array}{c}\sum_{i=1}^{N}\left(\sum_{k=1}^{M} v_{i k t} X_{i k}\right)-V T_{t}=0 \\
V T_{t+1} \geq V T_{t} \\
\sum_{i=1}^{N}\left(\sum_{k=1}^{M} q_{i k t} X_{i k}\right)-Q_{t}=0 \\
Q_{t+1} \leq Q_{t}\end{array}$ & $\begin{array}{c}\sum_{i=1}^{N}\left(\sum_{k=1}^{M} v_{i k t} X_{i k}\right)-V T_{t}=0 \\
V T_{t+1} \geq V T_{t} \\
\sum_{i=1}^{N}\left(\sum_{k=1}^{M} q_{i k t} X_{i k}\right)-D m a_{t}=Q \operatorname{Max}_{t}\end{array}$ \\
\hline
\end{tabular}

Quadro 2 - Estrutura matemática dos modelos estudados.

Os três modelos foram executados no Software Cplex e obteve-se então três resultados distintos, o primeiro que resulta no ordenamento da produção madeireira, e o segundo e terceiro que fazem o mesmo com controle do indicador hidrológico e contribuem para uma melhor qualidade do ecossistema florestal.

\subsection{Elaboração e comparação dos planos de corte}

Nesta etapa foram elaborados e comparados os planos de manejo dos três modelos estudados, incluindo também a verificação dos custos de implementação dessas estratégias.

Para a realização das análises dos resultados foram utilizados os "outputs" do Cplex e o Microsoft Access para cruzar informações entre os resultados dos modelos e os dados da área de estudo. 
O fluxograma a seguir resume e ilustra as etapas e as ferramentas utilizadas para a construção e análise dos modelos de programação linear utilizados neste estudo.

\section{DADOS DA ÁREA ESTUDADA}

Unidades de Gestão (UG): área, material genético, produtividade, idade e rotação do plantio Custos médios das atividades florestais e custo de madeira posto fábrica

$\checkmark \quad$ Idades mínimas e máximas de corte dos plantios e número de rotação mínimo e máximo permitido

$\checkmark \quad$ Taxa de rentabilidade do investimento

$\checkmark \quad$ Preço de venda da madeira por $\mathrm{m}^{3}$ sólido entregue na fábrica

$\checkmark \quad$ Tempo do horizonte de planejamento

\section{GERADOR}

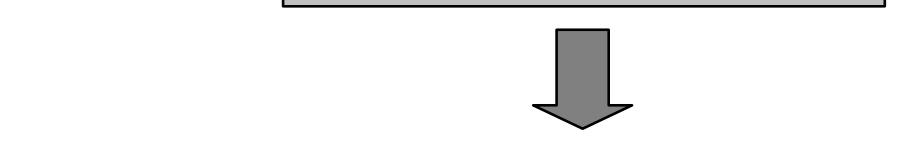

\section{PRODUTO DO GERADOR}

$\checkmark$ Geração dos regimes de manejo

$\checkmark$ Valoração econômica de cada regime

$\checkmark$ Composição da matriz de programação linear

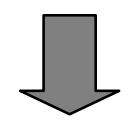

Cplex

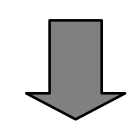

ACCESS : $\checkmark$ Cruza informações entre os resultados do Cplex e os dados da área de estudo. 


\section{RESULTADOS E DISCUSSÃO}

\subsection{Valor Total do Projeto, Fluxo de Produção de Madeira e Deflúvio}

Os resultados da execução dos três modelos de programação linear (M1, M2 e M3) foram analisados a partir dos relatórios gerados pelo Software Cplex.

Para a análise dos resultados utilizaram-se também os recursos do Microsoft Access (Tabelas relacionais) para cruzar informações de tabelas utilizadas no Software Gerador e tabelas geradas pelo Cplex.

O Modelo 1 (M1) se refere ao modelo básico de programação linear, ou seja, o modelo que maximiza o Valor Total do Projeto (VTP), possui restrições de área, restrições de produção não decrescente e equações que apenas quantificam o deflúvio ao longo do horizonte de planejamento.

Para a solução desse modelo, o Cplex exigiu 524 iterações e selecionou 48 regimes de manejo que serão adotados para a elaboração dos planos de corte.

O VTP foi de R $\$ 43,93$ milhões, produzindo $363 \mathrm{mil} \mathrm{m}^{3}$ de madeira por ano. A variação do deflúvio nos 14 anos ficou dentro do seguinte intervalo: mínimo 5,76 milhões de $\mathrm{m}^{3}$.ano ${ }^{-1}$ e máximo de 9,72 milhões de $\mathrm{m}^{3} . \mathrm{ano}^{-1}$. O fluxo de produção de madeira $\left(\mathrm{m}^{3}\right.$.ano $\left.{ }^{-1}\right)$ e deflúvio $\left(\mathrm{m}^{3}\right.$.ano $\left.{ }^{-1}\right)$ são apresentados na Figura 3. 


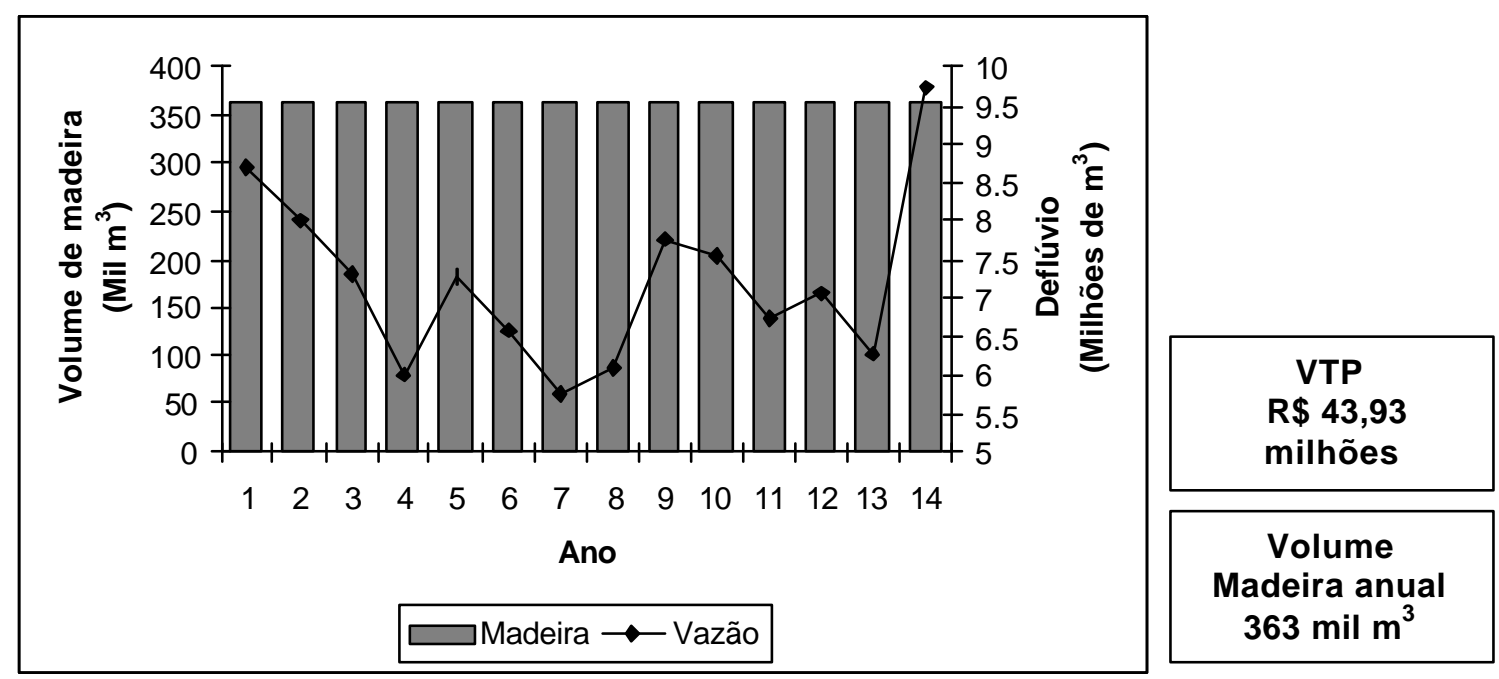

Figura 3 - Fluxo de produção de madeira e deflúvio no horizonte de planejamento (Modelo 1).

O Modelo 2 (M2) acrescenta ao modelo básico de programação linear as restrição hidrológicas de deflúvio impondo produção de água não crescente ao longo do horizonte de planejamento.

Para a solução desse modelo o programa Cplex exigiu 877 iterações e foram selecionados para compor o plano de corte 56 regimes de manejo.

O VTP foi de R \$43,75 milhões e o volume anual de madeira produzido ao longo do horizonte de planejamento foi de $362 \mathrm{mil} \mathrm{m}^{3}$. A variação do deflúvio nos 14 anos ficou dentro do seguinte intervalo: mínimo 7,17 milhões de $\mathrm{m}^{3}$.ano ${ }^{-1}$ e máximo de 8,70 milhões de $\mathrm{m}^{3}$.ano ${ }^{-1}$. O fluxo de produção de madeira $\left(\mathrm{m}^{3}\right.$.ano $\left.{ }^{-1}\right)$ e deflúvio $\left(\mathrm{m}^{3}\right.$.ano $\left.{ }^{-1}\right)$ são apresentados na Figura 4. 


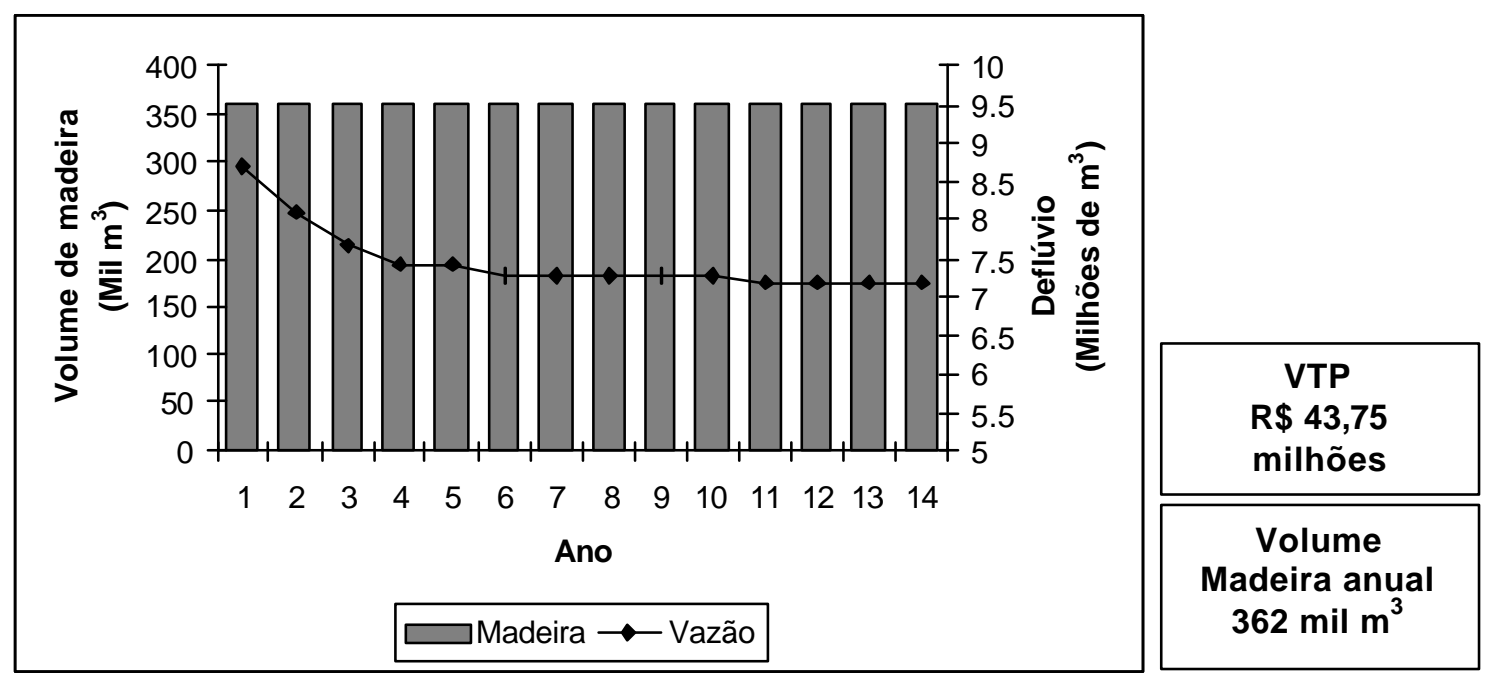

Figura 4 - Fluxo de produção de madeira e deflúvio no horizonte de planejamento (Modelo 2).

O Modelo 3 (M3) acrescenta ao modelo básico de programação linear penalidades caso a cota máxima estabelecida para o deflúvio na restrição hidrológica $\left(3,13\right.$ milhões $\mathrm{m}^{3} \cdot$ ano $\left.^{-1}\right)$ seja superada. Para a solução desse modelo, o programa Cplex exigiu 685 iterações e foram selecionados para compor o plano de corte 48 regimes de manejo.

O VTP foi de R \$ 42,65 milhões e o volume anual de madeira produzido ao longo do horizonte de planejamento foi de $356 \mathrm{mil} \mathrm{m}^{3}$. A variação do deflúvio nos 14 anos ficou dentro do seguinte intervalo: mínimo 5,31 milhões de $\mathrm{m}^{3}$.ano ${ }^{-1}$ e máximo de 8,70 milhões de $\mathrm{m}^{3}$.ano ${ }^{-1}$. O fluxo de produção de madeira $\left(\mathrm{m}^{3}\right.$.ano $\left.{ }^{-1}\right)$ e deflúvio $\left(\mathrm{m}^{3}\right.$.ano $\left.{ }^{-1}\right)$ são apresentadas na Figura 5. 


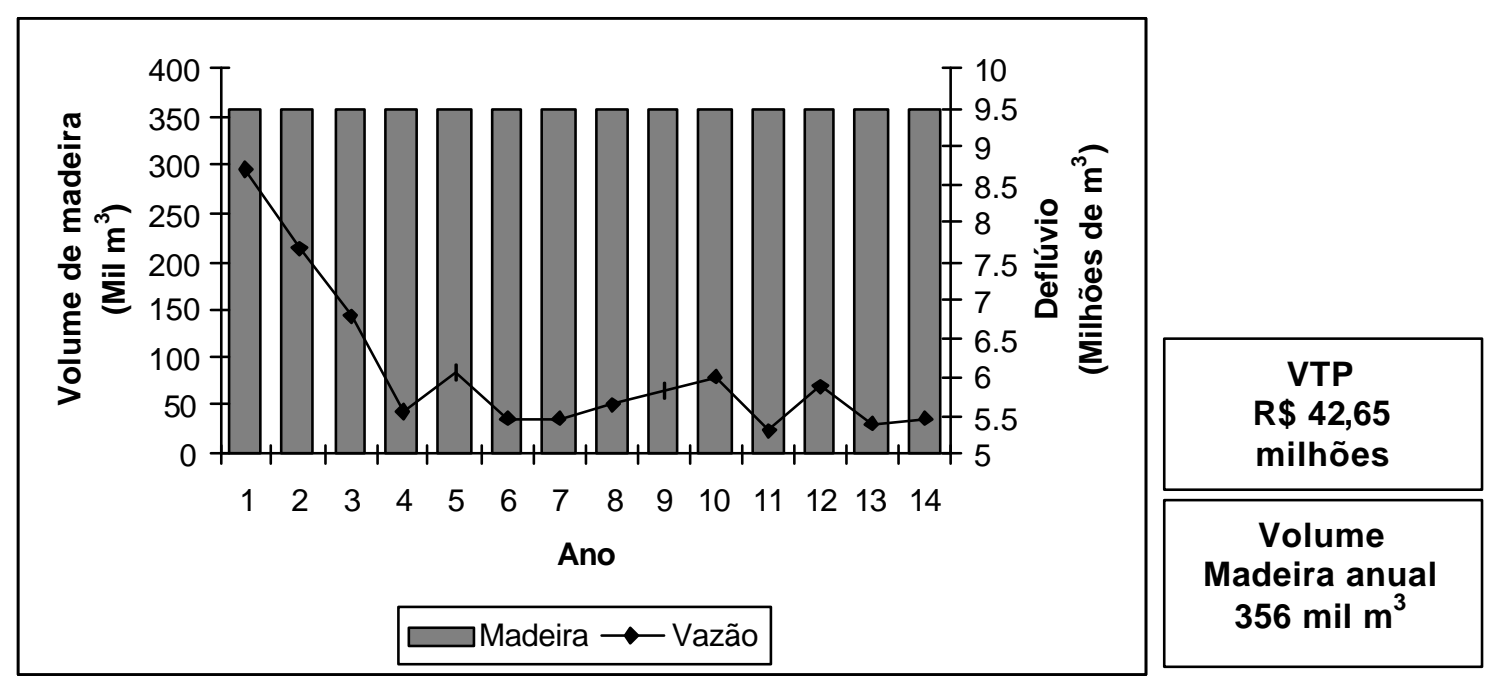

Figura 5 - Fluxo de produção de madeira e deflúvio no horizonte de planejamento (Modelo 3).

A comparação entre as variações do fluxo do deflúvio resultante de cada modelo pode ser visualizada na Figura 6.

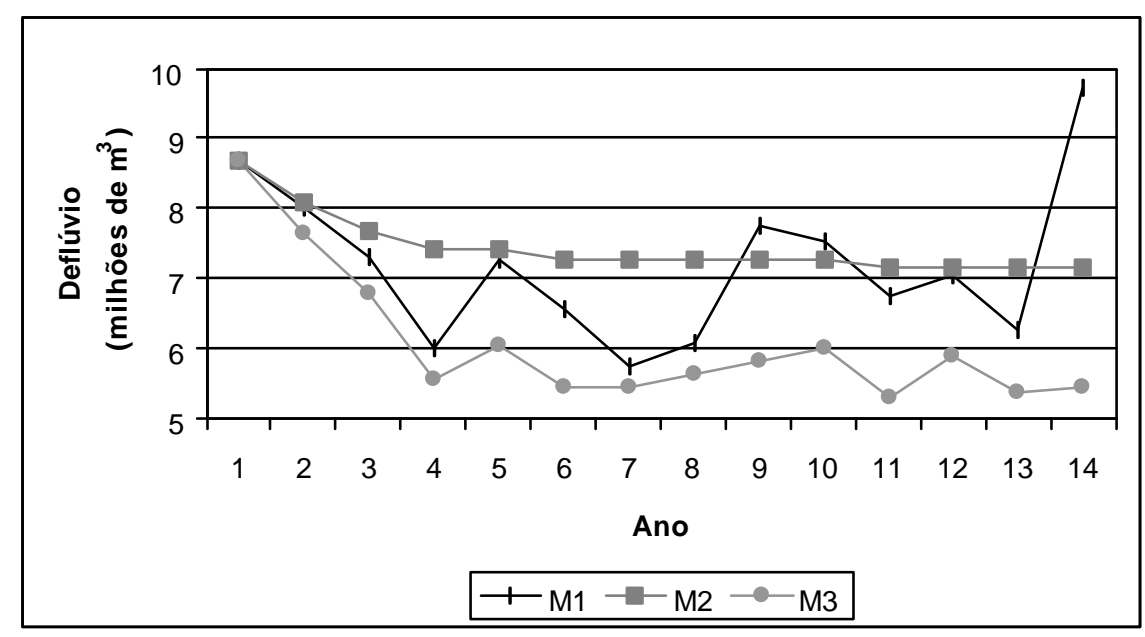

Figura 6 - Comparação entre os fluxos de deflúvio resultantes dos modelos M1, M2 e M3 respectivamente.

O modelo 1 (M1), por não apresentar restrições hidrológicas, enfatiza a escolha de regimes de mais alto valor e gera um fluxo de deflúvio bastante irregular. Como resultado observam-se amplas variações no deflúvio ao longo do horizonte de planejamento, sendo que a diferença entre o maior e menor valor foi de 3,96 milhões de 
$\mathrm{m}^{3}$. Essas variações não são interessantes para a gestão da floresta quando se fala na preservação dos recursos hídricos.

Observa-se que o modelo 2 (M2) regularizou o deflúvio ao longo do horizonte de planejamento, o que ficou mais evidente após o quarto ano, porém essa regularização se fez em um nível alto (média de 7,45 milhões de $\mathrm{m}^{3}$.ano-1 ${ }^{-1}$. O nível elevado do deflúvio também não é apropriado pois ele é resultado de uma baixa cobertura vegetal na área e acelera o processo de erosão do solo.

O modelo M3 é o que melhor se enquadra na proposta de preservação dos recursos hídricos pois ele minimiza a produção de água ao longo do horizonte de planejamento, mantendo uma maior cobertura vegetal na área e evitando riscos de erosão nos períodos mais chuvosos do ano. A manutenção da floresta por um maior período de tempo pode reduzir a entrada de poluentes e sedimentos nos cursos de água, favorecendo a infiltração da água no solo, absorvendo, retardando ou purificando o escoamento antes que ele atinja os rios.

A amplitude de variação entre a maior e a menor cota do deflúvio no modelo 3 foi de 3,38 milhões de $\mathrm{m}^{3}$ quando observados os 14 anos. No entanto, quando se analisa o fluxo de deflúvio a partir do quarto ano do horizonte de planejamento, observa-se que a amplitude de variação cai para $685 \mathrm{mil} \mathrm{m}^{3}$.

O impacto do controle de deflúvio sobre o VTP pode ser verificado na Figura 7. Observa-se que houve uma queda de $0,41 \%$ no VTP do M2 quando comparado ao M1 e uma queda de 2,91\% no VTP do M3 quando comparado ao M1. Esses valores percentuais correspondem a uma quantia de $\mathrm{R} \$ 180$ mil e $\mathrm{R} \$ 1,2$ milhões respectivamente.

$\mathrm{O}$ valor de R \$ 1,2 milhões representa o custo da implementação do modelo 3 que tem como finalidade ordenar a produção madeireira além de controlar o indicador hidrológico diminuindo do processo erosivo do solo e contribuir para uma melhor qualidade do ecossistema florestal. Esse valor é a diferença entre o VTP resultante do modelo 1 e modelo 3 . 


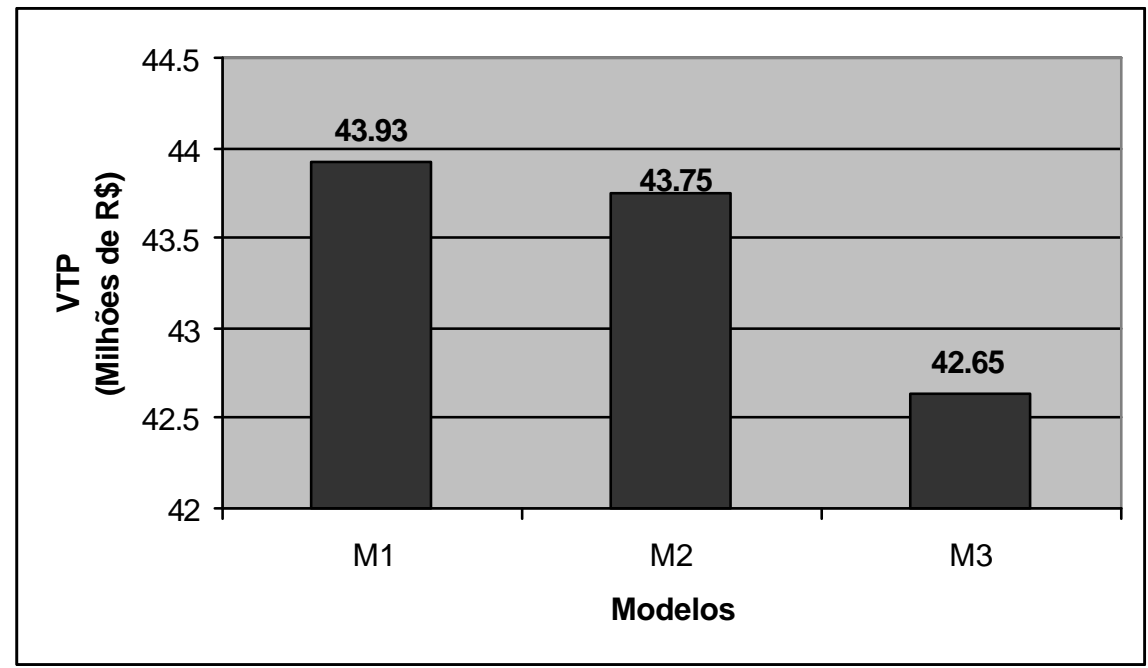

Figura 7 - Valor Total do Projeto resultante dos modelos 1, 2 e 3 (M1, M2 e M3).

A produção anual de madeira dos modelos 2 e 3 foi inferior à produção do modelo 1. A queda de produção de madeira foi de $1000 \mathrm{~m}^{3}$ (0,28\%) do modelo 1 para o modelo 2, e de $7636 \mathrm{~m}^{3}$ (1,93\%) do modelo 1 para o modelo 3 (Figura 8).

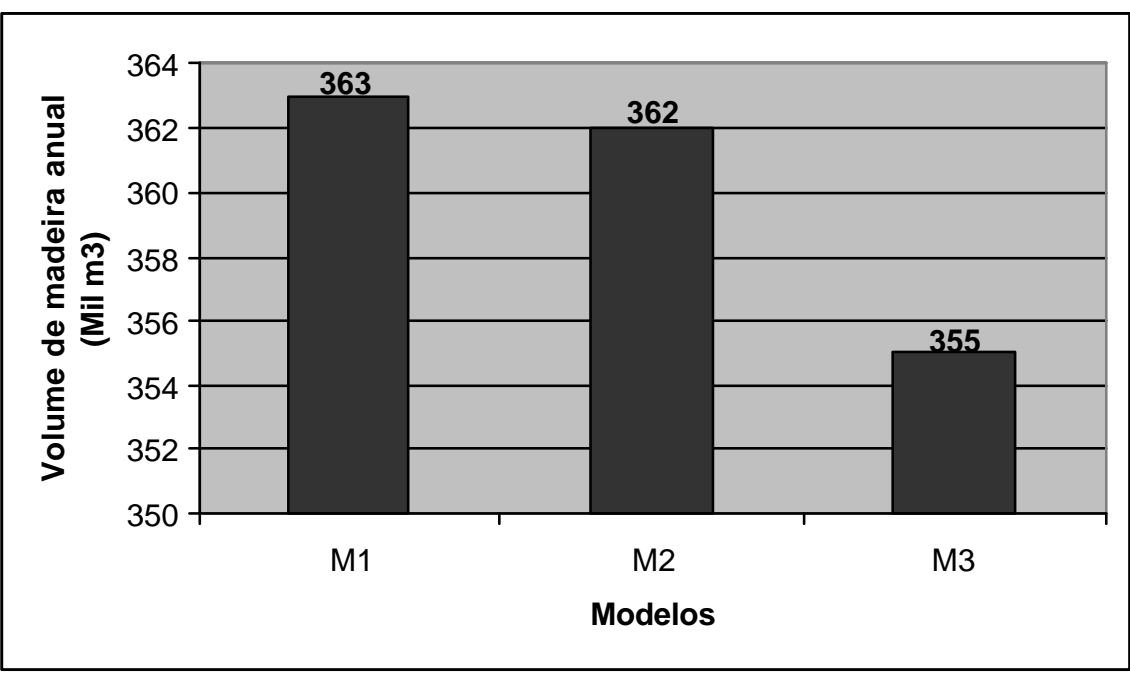

Figura 8 - Volume de madeira $\left(\mathrm{mil} \mathrm{m}^{3}\right)$ produzido anualmente por cada modelo. 
Tanto o Valor Total do Projeto quanto a produção de madeira anual podem aumentar caso a cota máxima permitida do deflúvio seja alterada para um valor maior. Por isso é de grande importância identificar qual é o valor ideal do deflúvio que represente bem a situação da área coberta por floresta nativa.

\subsection{Elaboração e comparação dos planos de corte.}

O plano de colheita auxilia o gestor florestal nas atividades de manejo e planejamento, indicando quando (ano), como (regime) e quais as áreas que serão cortadas (UG). O plano de colheita resultante dos modelos 1, 2 e 3 referente ao primeiro ano do horizonte de planejamento pode ser visualizado nas Tabelas 9, 10 e 11 respectivamente. Essas tabelas descrevem as Unidades de Gestão (UG) que serão cortadas, os regimes de manejo escolhidos para cada UG, os volumes totais cortados nas UGs e as operações florestais que serão adotadas após os cortes.

Os planos de colheita na integra resultantes dos modelos 1, 2 e 3 podem ser encontrados no Anexo A, B e C respectivamente.

Tabela 9. Plano de colheita referente ao primeiro ano de planejamento resultante do Modelo 1.

\begin{tabular}{|c|c|c|c|c|}
\hline UG & Regime & $\begin{array}{c}\text { Área cortada } \\
\text { (ha) }\end{array}$ & $\begin{array}{c}\text { Volume total } \\
\text { de madeira }\left(\mathrm{m}^{3}\right)\end{array}$ & Operação florestal \\
\hline 8 & 23 & 86,10 & 17220,00 & Condução \\
\hline 17 & 22 & 7,13 & 1861,79 & Reforma \\
\hline 21 & 39 & 82,00 & 21976,00 & Reforma \\
\hline 22 & 24 & 78,98 & 26695,24 & Reforma \\
\hline 23 & 39 & 145,79 & 41987,52 & Reforma \\
\hline 24 & 23 & 290,04 & 76860,60 & Reforma \\
\hline 27 & 27 & 320,12 & 137971,72 & Reforma \\
\hline 29 & 38 & 159,52 & 32542,08 & Reforma \\
\hline 33 & 23 & 30,00 & 6330,00 & Condução \\
\hline Total & & 1199,68 & 363445,00 & \\
\hline
\end{tabular}


Tabela 10. Plano de colheita referente ao primeiro ano de planejamento resultante do Modelo 2.

\begin{tabular}{ccccc}
\hline UG & Regime & $\begin{array}{c}\text { Área cortada } \\
\text { (ha) }\end{array}$ & $\begin{array}{c}\text { Volume total } \\
\left.\text { de madeira } \mathbf{( m}^{\mathbf{3}}\right)\end{array}$ & Operação florestal \\
\hline 2 & 37 & 1,36 & 314,25 & Reforma \\
8 & 23 & 86,10 & 17220,00 & Condução \\
17 & 37 & 92,84 & 24231,29 & Reforma \\
21 & 39 & 82,00 & 21976,00 & Reforma \\
22 & 21 & 78,98 & 26695,24 & Reforma \\
23 & 39 & 145,79 & 41987,52 & Reforma \\
24 & 23 & 290,04 & 76860,60 & Reforma \\
27 & 27 & 264,47 & 113984,67 & Reforma \\
29 & 38 & 159,52 & 32542,08 & Reforma \\
33 & 23 & 30,00 & 6330,00 & Condução \\
Total & & $\mathbf{1 2 3 1 , 1 0}$ & $\mathbf{3 6 2 1 4 1 , 6 6}$ & \\
\hline
\end{tabular}

Tabela 11. Plano de colheita referente ao primeiro ano de planejamento resultante do Modelo 3.

\begin{tabular}{ccccc}
\hline UG & Regime & $\begin{array}{c}\text { Área cortada } \\
\text { (ha) }\end{array}$ & $\begin{array}{c}\text { Volume total } \\
\text { de madeira }\left(\mathbf{m}^{\mathbf{3}}\right)\end{array}$ & Operação florestal \\
\hline 6 & 20 & 55,54 & 13830,16 & Reforma \\
6 & 21 & 3,90 & 971,62 & Reforma \\
7 & 19 & 156,13 & 31382,13 & Reforma \\
8 & 20 & 86,10 & 17220,00 & Condução \\
17 & 3 & 128,00 & 33408,52 & Reforma \\
17 & 5 & 278,09 & 72582,51 & Reforma \\
17 & 19 & 6,17 & 1609,67 & Reforma \\
17 & 21 & 53,06 & 13847,82 & Reforma \\
19 & 20 & 180,11 & 41425,30 & Reforma \\
21 & 20 & 82,00 & 21976,00 & Reforma \\
22 & 21 & 78,98 & 26695,24 & Reforma \\
23 & 21 & 145,79 & 41987,52 & Reforma \\
29 & 20 & 159,52 & 32542,08 & Reforma \\
33 & 20 & 30,00 & 6330,00 & Condução \\
Total & & $\mathbf{1 4 4 3 , 3 9}$ & $\mathbf{3 5 5 8 0 8 , 5 7}$ & \\
\hline
\end{tabular}

Outro ponto importante quando tratamos de plano de corte é a idade que o eucalipto está sendo cortado. Quando comparados os modelos foi observado que os modelos 1 e 2 cortam a maioria de suas áreas com idades de 6 e 7 anos e no modelo 3 ocorreu um aumento nas áreas cortadas com idades de 7 anos (68\%), Figura 9. 
O período maior de permanência das árvores em pé justificam o menor escoamento superficial na floresta.

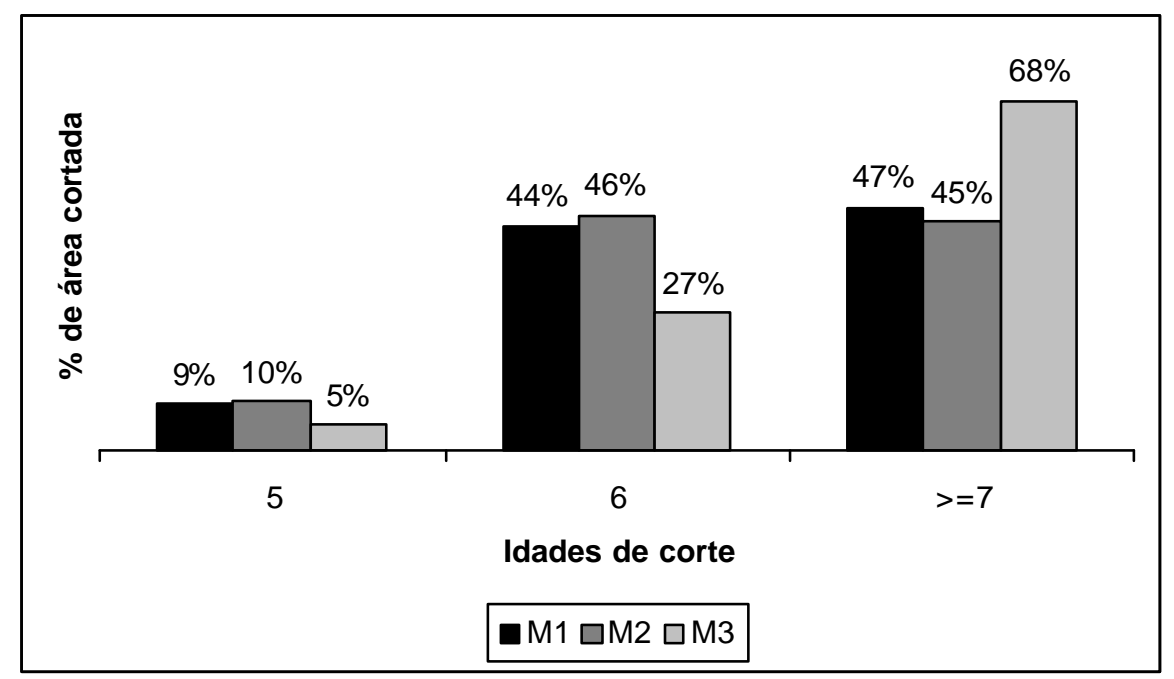

Figura 9 - Porcentagem de área cortada com 5, 6 e 7 anos de idade em cada modelo.

A partir da análise dos resultados pode-se dizer que a inclusão das restrições hidrológicas no modelo afetou o manejo, alterou o fluxo de produção de madeira e resultou em valores presente líquidos globais diferentes para cada modelo, confirmando então a principal hipótese do trabalho. 


\section{CONCLUSÕES}

Três modelos matemáticos de programação linear foram desenvolvidos para auxiliar o processo de tomada de decisão nas atividades de manejo e planejamento da produção florestal: um para o ordenamento simples da produção madeireira, e dois modelos alternativos que enfatizam a uniformização do deflúvio anual.

Os três modelos distinguem-se quanto à forma como a restrição hidrológica é considerada: no primeiro não há restrições hidrológicas, apenas equações que quantificam o deflúvio; no segundo as restrições hidrológicas tornam os deflúvios não crescentes ao longo do horizonte de planejamento; e no terceiro minimiza-se os desvios de uma cota de deflúvio preestabelecida.

Os resultados permitem concluir que a consideração do indicador hidrológico no planejamento de povoamentos florestais voltados para o abastecimento industrial, afetou o manejo, alterou o fluxo de produção de madeira e o plano de colheita, além de resultar em valores presentes líquidos globais diferentes para cada modelo, confirmando então a principal hipótese do trabalho.

Do ponto de vista do planejamento florestal o modelo 3 (M3), embora tenha apresentado o menor VTP, foi o que melhor se enquadrou na proposta de preservação dos recursos hídricos. Esse modelo minimiza a produção de água ao longo do horizonte de planejamento, mantendo uma maior cobertura vegetal na área evitando assim, riscos de erosão nos períodos mais chuvosos do ano. 
A diferença entre o maior VTP do modelo 1 e o menor do modelo 3 ( R \$ 1,2 milhões) representa o custo de se implementar um plano de colheita que tem como finalidade ordenar a produção madeireira e controlar o indicador hidrológico. As perdas com o solo e a conseqüente perda de qualidade do ecossistema florestal, se evitadas, justificariam esse investimento.

Os resultados aqui obtidos contemplam a situação de uma pequena região do Vale do Paraíba. Não se recomenda que as conclusões aqui obtidas sejam extrapoladas para outras condições de solo, relevo, precipitação, deflúvio e vegetação.

A utilização de indicadores hidrológicos enriquece os modelos de programação linear usados para o planejamento florestal e contribuem para um maior controle dos impactos ambientais.

A unidade básica de manejo, ou seja, a microbacia pode servir como laboratório natural para que se descubram novos indicadores e mais precisas relações quantitativas entre as atividades produtivas e as conservacionistas.

Ainda que se tratando de um pequeno avanço rumo ao uso sustentado dos recursos florestais, este trabalho apresenta uma nova abordagem e contribui para um maior controle das intervenções sobre os ecossistemas florestais. 
ANEXOS 
ANEXO A - Plano de coheita resultante do Modelo 1

Plano de colheita referente ao primeiro ano de planejamento.

\begin{tabular}{ccccc}
\hline UG & Regime & $\begin{array}{c}\text { Área cortada } \\
\text { (ha) }\end{array}$ & $\begin{array}{c}\text { Volume total } \\
\left.\text { de madeira } \mathbf{( m}^{\mathbf{3}}\right)\end{array}$ & Operação florestal \\
\hline 8 & 23 & 86,10 & 17220,00 & Condução \\
17 & 22 & 7,13 & 1861,79 & Reforma \\
21 & 39 & 82,00 & 21976,00 & Reforma \\
22 & 24 & 78,98 & 26695,24 & Reforma \\
23 & 39 & 145,79 & 41987,52 & Reforma \\
24 & 23 & 290,04 & 76860,60 & Reforma \\
27 & 27 & 320,12 & 137971,72 & Reforma \\
29 & 38 & 159,52 & 32542,08 & Reforma \\
33 & 23 & 30,00 & 6330,00 & Condução \\
Total & & $\mathbf{1 1 9 9 , 6 8}$ & $\mathbf{3 6 3 4 4 5 , 0 0}$ & \\
\hline
\end{tabular}

Plano de colheita referente ao segundo ano de planejamento.

\begin{tabular}{ccccc}
\hline UG & Regime & $\begin{array}{c}\text { Área cortada } \\
(\mathbf{h a})\end{array}$ & $\begin{array}{c}\text { Volume total } \\
\left.\text { de madeira } \mathbf{( m}^{\mathbf{3}}\right)\end{array}$ & Operação florestal \\
\hline 2 & 65 & 39,33 & 10107,81 & Reforma \\
5 & 69 & 139,00 & 29746,00 & Reforma \\
6 & 67 & 123,78 & 34288,20 & Reforma \\
6 & 69 & 87,45 & 24222,51 & Reforma \\
7 & 69 & 156,13 & 34973,12 & Reforma \\
17 & 52 & 302,44 & 88008,88 & Reforma \\
17 & 57 & 155,75 & 45323,45 & Reforma \\
19 & 69 & 180,11 & 46108,16 & Reforma \\
30 & 61 & 52,21 & 17749,73 & Reforma \\
30 & 67 & 96,81 & 32917,07 & Reforma \\
Total & & $\mathbf{1 3 3 3 , 0 1}$ & $\mathbf{3 6 3 4 4 4 , 9 3}$ & \\
\hline
\end{tabular}

Plano de colheita referente ao terceiro ano de planejamento.

\begin{tabular}{ccccc}
\hline UG & Regime & $\begin{array}{c}\text { Área cortada } \\
\text { (ha) }\end{array}$ & $\begin{array}{c}\text { Volume total } \\
\left.\text { de madeira } \mathbf{( m}^{\mathbf{3}}\right)\end{array}$ & Operação florestal \\
\hline 9 & 45 & 340,22 & 112271,38 & Reforma \\
20 & 88 & 75,00 & 25275,00 & Reforma \\
28 & 78 & 234,07 & 76072,95 & Reforma \\
28 & 80 & 418,60 & 136044,81 & Reforma \\
32 & 87 & 52,20 & 13780,80 & Reforma \\
Total & & $\mathbf{1 1 2 0 , 0 9}$ & $\mathbf{3 6 3 4 4 4 , 9 3}$ & \\
\hline
\end{tabular}


Plano de colheita referente ao quarto ano de planejamento.

\begin{tabular}{ccccc}
\hline UG & Regime & $\begin{array}{c}\text { Área cortada } \\
\text { (ha) }\end{array}$ & $\begin{array}{c}\text { Volume total } \\
\text { de madeira } \mathbf{( m}^{\mathbf{3}} \mathbf{)}\end{array}$ & Operação florestal \\
\hline 9 & 61 & 29,23 & 10728,77 & Reforma \\
10 & 60 & 339,08 & 87143,56 & Reforma \\
15 & 59 & 14,10 & 3665,51 & Reforma \\
15 & 60 & 179,00 & 46540,49 & Reforma \\
16 & 27 & 467,70 & 142647,83 & Reforma \\
18 & 53 & 121,99 & 37571,50 & Reforma \\
18 & 59 & 114,11 & 35147,30 & Reforma \\
Total & & $\mathbf{1 2 6 5 , 2 1}$ & $\mathbf{3 6 3 4 4 4 , 9 6}$ & \\
\hline
\end{tabular}

Plano de colheita referente ao quinto ano de planejamento.

\begin{tabular}{ccccc}
\hline UG & Regime & $\begin{array}{c}\text { Área cortada } \\
(\mathbf{h a})\end{array}$ & $\begin{array}{c}\text { Volume total } \\
\text { de madeira }\left(\mathbf{m}^{\mathbf{3}}\right)\end{array}$ & Operação florestal \\
\hline 4 & 15 & 249,42 & 76074,35 & Reforma \\
11 & 38 & 416,22 & 126946,58 & Reforma \\
11 & 39 & 250,87 & 76515,87 & Reforma \\
12 & 37 & 206,00 & 67156,00 & Reforma \\
13 & 15 & 41,07 & 14785,20 & Reforma \\
16 & 37 & 5,80 & 1966,95 & Reforma \\
Total & & $\mathbf{1 1 6 9 , 3 9}$ & $\mathbf{3 6 3 4 4 4 , 9 5}$ & \\
\hline
\end{tabular}

Plano de colheita referente ao sexto ano de planejamento.

\begin{tabular}{ccccc}
\hline UG & Regime & $\begin{array}{c}\text { Área cortada } \\
\text { (ha) }\end{array}$ & $\begin{array}{c}\text { Volume total } \\
\text { de madeira } \mathbf{( m}^{\mathbf{3}} \mathbf{)}\end{array}$ & Operação florestal \\
\hline 1 & 12 & 118,15 & 37571,70 & Reforma \\
3 & 12 & 311,86 & 95116,63 & Reforma \\
4 & 24 & 12,49 & 4232,72 & Reforma \\
14 & 17 & 104,69 & 27114,71 & Condução \\
25 & 30 & 51,51 & 16328,67 & Reforma \\
26 & 12 & 20,45 & 6237,80 & Reforma \\
27 & 27 & 320,12 & 137971,72 & Condução \\
31 & 29 & 123,40 & 38871,00 & Reforma \\
Total & & $\mathbf{1 0 6 2 , 6 7}$ & $\mathbf{3 6 3 4 4 4 , 9 5}$ & \\
\hline
\end{tabular}

Plano de colheita referente ao sétimo ano de planejamento.

\begin{tabular}{ccccc}
\hline UG & Regime & $\begin{array}{c}\text { Área cortada } \\
\text { (ha) }\end{array}$ & $\begin{array}{c}\text { Volume total } \\
\text { de madeira } \mathbf{( m}^{\mathbf{3}} \text { ) }\end{array}$ & Operação florestal \\
\hline 3 & 21 & 62,74 & 21269,61 & Reforma \\
26 & 25 & 55,10 & 18513,00 & Reforma \\
30 & 61 & 52,21 & 17749,73 & Condução \\
35 & 26 & 800,00 & 224000,00 & Reforma \\
36 & 26 & 260,04 & 81912,60 & Reforma \\
Total & & $\mathbf{1 2 3 0 , 0 9}$ & $\mathbf{3 6 3 4 4 4 , 9 4}$ & \\
\hline
\end{tabular}


Plano de colheita referente ao oitavo ano de planejamento.

\begin{tabular}{ccccc}
\hline UG & Regime & $\begin{array}{c}\text { Área cortada } \\
\text { (ha) }\end{array}$ & $\begin{array}{c}\text { Volume total } \\
\text { de madeira }\left(\mathbf{m}^{\mathbf{3}}\right)\end{array}$ & Operação florestal \\
\hline 2 & 65 & 39,33 & 7708,68 & Condução \\
6 & 67 & 123,78 & 26242,23 & Condução \\
8 & 23 & 86,10 & 18511,50 & Reforma \\
17 & 22 & 7,13 & 2075,79 & Reforma \\
17 & 52 & 302,44 & 78935,80 & Reforma \\
21 & 39 & 82,00 & 17384,00 & Condução \\
22 & 24 & 78,98 & 26695,24 & Reforma \\
23 & 39 & 145,79 & 33385,91 & Condução \\
24 & 23 & 290,04 & 85271,76 & Reforma \\
29 & 38 & 159,52 & 27596,96 & Condução \\
30 & 67 & 96,81 & 32917,07 & Condução \\
33 & 23 & 30,00 & 6720,00 & Reforma \\
Total & & 1441,93 & 363444,93 & \\
\hline
\end{tabular}

Plano de colheita referente ao nono ano de planejamento.

\begin{tabular}{ccccc}
\hline UG & Regime & $\begin{array}{c}\text { Área cortada } \\
\text { (ha) }\end{array}$ & $\begin{array}{c}\text { Volume total } \\
\text { de madeira }\left(\mathbf{m}^{3}\right)\end{array}$ & Operação florestal \\
\hline 5 & 69 & 139,00 & 25298,00 & Condução \\
6 & 69 & 87,45 & 20549,79 & Condução \\
7 & 69 & 156,13 & 29664,70 & Condução \\
9 & 45 & 340,22 & 112271,38 & Reforma \\
17 & 57 & 155,75 & 45323,45 & Reforma \\
19 & 69 & 180,11 & 39263,98 & Condução \\
20 & 88 & 75,00 & 22725,00 & Reforma \\
28 & 78 & 234,07 & 68348,62 & Reforma \\
Total & & 1367,72 & 363444,91 & \\
\hline
\end{tabular}

Plano de colheita referente ao décimo ano de planejamento.

\begin{tabular}{ccccc}
\hline UG & Regime & $\begin{array}{c}\text { Área cortada } \\
\text { (ha) }\end{array}$ & $\begin{array}{c}\text { Volume total } \\
\text { de madeira } \mathbf{( m}^{\mathbf{3}} \mathbf{)}\end{array}$ & Operação florestal \\
\hline 9 & 61 & 29,23 & 9647,12 & Reforma \\
15 & 59 & 14,10 & 2805,52 & Condução \\
16 & 27 & 467,70 & 142647,83 & Reforma \\
18 & 53 & 121,99 & 33789,96 & Reforma \\
18 & 59 & 114,11 & 26816,93 & Condução \\
28 & 80 & 418,60 & 136044,81 & Reforma \\
32 & 87 & 52,20 & 11692,80 & Condução \\
Total & & 1217,93 & 363444,96 & \\
\hline
\end{tabular}


Plano de colheita referente ao décimo primeiro ano de planejamento.

\begin{tabular}{ccccc}
\hline UG & Regime & $\begin{array}{c}\text { Área cortada } \\
\text { (ha) }\end{array}$ & $\begin{array}{c}\text { Volume total } \\
\left.\text { de madeira } \mathbf{( m}^{\mathbf{3}}\right)\end{array}$ & Operação florestal \\
\hline 4 & 15 & 249,42 & 76074,35 & Reforma \\
10 & 60 & 339,08 & 73919,44 & Condução \\
11 & 38 & 416,22 & 96978,86 & Condução \\
12 & 37 & 206,00 & 60358,00 & Reforma \\
13 & 15 & 41,07 & 14785,20 & Reforma \\
15 & 60 & 179,00 & 39559,42 & Condução \\
16 & 37 & 5,80 & 1769,67 & Reforma \\
Total & & $\mathbf{1 4 3 6 , 6 0}$ & $\mathbf{3 6 3 4 4 4 , 9 5}$ & \\
\hline
\end{tabular}

Plano de colheita referente ao décimo segundo ano de planejamento.

\begin{tabular}{ccccc}
\hline UG & Regime & $\begin{array}{c}\text { Área cortada } \\
(\mathbf{h a})\end{array}$ & $\begin{array}{c}\text { Volume total } \\
\text { de madeira }\left(\mathbf{m}^{\mathbf{3}}\right)\end{array}$ & Operação florestal \\
\hline 1 & 12 & 118,15 & 37571,70 & Reforma \\
3 & 12 & 311,86 & 95116,63 & Reforma \\
4 & 24 & 12,49 & 3808,20 & Reforma \\
11 & 39 & 250,87 & 64975,77 & Condução \\
14 & 17 & 104,69 & 28685,06 & Reforma \\
26 & 12 & 20,45 & 6237,80 & Reforma \\
26 & 25 & 55,10 & 12231,80 & Condução \\
27 & 27 & 320,12 & 84831,80 & Reforma \\
31 & 29 & 123,40 & 29986,20 & Condução \\
Total & & $\mathbf{1 3 1 7 , 1 3}$ & $\mathbf{3 6 3 4 4 4 , 9 6}$ & \\
\hline
\end{tabular}

Plano de colheita referente ao décimo terceiro ano de planejamento.

\begin{tabular}{ccccc}
\hline UG & Regime & $\begin{array}{c}\text { Área cortada } \\
\text { (ha) }\end{array}$ & $\begin{array}{c}\text { Volume total } \\
\text { de madeira } \mathbf{( m}^{\mathbf{3}} \mathbf{)}\end{array}$ & Operação florestal \\
\hline 2 & 65 & 39,33 & 8141,31 & Reforma \\
3 & 21 & 62,74 & 19136,37 & Reforma \\
17 & 22 & 7,13 & 1333,93 & Condução \\
17 & 52 & 302,44 & 56555,53 & Condução \\
22 & 24 & 78,98 & 17138,66 & Condução \\
25 & 30 & 51,51 & 13856,19 & Condução \\
30 & 61 & 52,21 & 10493,23 & Reforma \\
35 & 26 & 800,00 & 173600,00 & Condução \\
36 & 26 & 260,04 & 63189,72 & Condução \\
Total & & $\mathbf{1 6 5 4 , 3 8}$ & $\mathbf{3 6 3 4 4 4 , 9 4}$ & \\
\hline
\end{tabular}


Plano de colheita referente ao décimo quarto ano de planejamento.

\begin{tabular}{ccccc}
\hline UG & Regime & $\begin{array}{c}\text { Área cortada } \\
\text { (ha) }\end{array}$ & $\begin{array}{c}\text { Volume total } \\
\text { de madeira } \mathbf{( m}^{\mathbf{3}} \mathbf{)}\end{array}$ & Operação florestal \\
\hline 6 & 67 & 123,78 & 30822,24 & Reforma \\
8 & 23 & 86,10 & 14464,80 & Condução \\
9 & 45 & 340,22 & 79950,83 & Condução \\
17 & 57 & 155,75 & 29125,38 & Condução \\
20 & 88 & 75,00 & 16275,00 & Condução \\
21 & 39 & 82,00 & 18450,00 & Reforma \\
23 & 39 & 145,79 & 35281,18 & Reforma \\
24 & 23 & 290,04 & 65259,00 & Condução \\
28 & 78 & 234,07 & 48686,68 & Condução \\
30 & 67 & 96,81 & 19459,79 & Reforma \\
33 & 23 & 30,00 & 5670,00 & Condução \\
Total & & $\mathbf{1 6 5 9 , 5 7}$ & $\mathbf{3 6 3 4 4 4 , 9 1}$ & \\
\hline
\end{tabular}


ANEXO B - Plano de colheita resultante do Modelo 2

Plano de colheita referente ao primeiro ano de planejamento.

\begin{tabular}{ccccc}
\hline UG & Regime & $\begin{array}{c}\text { Área cortada } \\
\text { (ha) }\end{array}$ & $\begin{array}{c}\text { Volume total } \\
\left.\text { de madeira } \mathbf{( m}^{\mathbf{3}}\right)\end{array}$ & Operação florestal \\
\hline 2 & 37 & 1,36 & 314,25 & Reforma \\
8 & 23 & 86,10 & 17220,00 & Condução \\
17 & 37 & 92,84 & 24231,29 & Reforma \\
21 & 39 & 82,00 & 21976,00 & Reforma \\
22 & 21 & 78,98 & 26695,24 & Reforma \\
23 & 39 & 145,79 & 41987,52 & Reforma \\
24 & 23 & 290,04 & 76860,60 & Reforma \\
27 & 27 & 264,47 & 113984,67 & Reforma \\
29 & 38 & 159,52 & 32542,08 & Reforma \\
33 & 23 & 30,00 & 6330,00 & Condução \\
Total & & $\mathbf{1 2 3 1 , 1 0}$ & $\mathbf{3 6 2 1 4 1 , 6 6}$ & \\
\hline
\end{tabular}

Plano de colheita referente ao segundo ano de planejamento.

\begin{tabular}{ccccc}
\hline UG & Regime & $\begin{array}{c}\text { Área cortada } \\
\text { (ha) }\end{array}$ & $\begin{array}{c}\text { Volume total } \\
\text { de madeira }\left(\mathbf{m}^{\mathbf{3}}\right)\end{array}$ & Operação florestal \\
\hline 2 & 68 & 37,97 & 9758,19 & Reforma \\
5 & 69 & 139,00 & 29746,00 & Reforma \\
6 & 67 & 2,11 & 584,66 & Reforma \\
6 & 69 & 209,12 & 57926,05 & Reforma \\
7 & 69 & 156,13 & 34973,12 & Reforma \\
17 & 65 & 372,48 & 108391,62 & Reforma \\
19 & 69 & 180,11 & 46108,16 & Reforma \\
27 & 61 & 55,65 & 23987,05 & Reforma \\
30 & 61 & 30,76 & 10457,96 & Reforma \\
30 & 67 & 118,26 & 40208,84 & Reforma \\
Total & & $\mathbf{1 3 0 1 , 5 9}$ & $\mathbf{3 6 2 1 4 1 , 6 5}$ & \\
\hline
\end{tabular}

Plano de colheita referente ao terceiro ano de planejamento.

\begin{tabular}{ccccc}
\hline UG & Regime & $\begin{array}{c}\text { Área cortada } \\
\text { (ha) }\end{array}$ & $\begin{array}{c}\text { Volume total } \\
\text { de madeira }\left(\mathbf{m}^{\mathbf{3}}\right)\end{array}$ & Operação florestal \\
\hline 9 & 45 & 261,62 & 86336,22 & Reforma \\
10 & 48 & 106,63 & 24631,90 & Reforma \\
20 & 88 & 75,00 & 25275,00 & Reforma \\
28 & 78 & 137,63 & 44729,56 & Reforma \\
28 & 85 & 246,80 & 80211,56 & Reforma \\
28 & 87 & 268,24 & 87176,60 & Reforma \\
32 & 87 & 52,20 & 13780,80 & Reforma \\
Total & & $\mathbf{1 1 4 8 , 1 3}$ & $\mathbf{3 6 2 1 4 1 , 6 3}$ & \\
\hline
\end{tabular}


Plano de colheita referente ao quarto ano de planejamento.

\begin{tabular}{ccccc}
\hline UG & Regime & $\begin{array}{c}\text { Área cortada } \\
\text { (ha) }\end{array}$ & $\begin{array}{c}\text { Volume total } \\
\left.\text { de madeira } \mathbf{( m}^{\mathbf{3}}\right)\end{array}$ & Operação florestal \\
\hline 9 & 61 & 46,16 & 16942,48 & Reforma \\
9 & 63 & 61,66 & 22629,37 & Reforma \\
10 & 59 & 180,32 & 46343,17 & Reforma \\
10 & 60 & 52,12 & 13396,07 & Reforma \\
15 & 60 & 193,10 & 50206,00 & Reforma \\
16 & 27 & 458,71 & 139905,79 & Reforma \\
18 & 53 & 171,50 & 52822,09 & Reforma \\
18 & 59 & 64,60 & 19896,71 & Reforma \\
Total & & $\mathbf{1 2 2 8 , 1 8}$ & $\mathbf{3 6 2 1 4 1 , 6 7}$ & \\
\hline
\end{tabular}

Plano de colheita referente ao quinto ano de planejamento.

\begin{tabular}{ccccc}
\hline UG & Regime & $\begin{array}{c}\text { Área cortada } \\
(\mathbf{h a})\end{array}$ & $\begin{array}{c}\text { Volume total } \\
\text { de madeira }\left(\mathbf{m}^{\mathbf{3}}\right)\end{array}$ & Operação florestal \\
\hline 4 & 15 & 119,45 & 36430,94 & Reforma \\
11 & 38 & 598,29 & 182478,91 & Reforma \\
11 & 39 & 68,80 & 20983,51 & Reforma \\
12 & 37 & 206,00 & 67156,00 & Reforma \\
13 & 15 & 41,07 & 14785,20 & Reforma \\
16 & 37 & 14,79 & 5014,66 & Reforma \\
31 & 20 & 123,40 & 35292,40 & Reforma \\
Total & & $\mathbf{1 1 7 1 , 8 0}$ & $\mathbf{3 6 2 1 4 1 , 6 2}$ & \\
\hline
\end{tabular}

Plano de colheita referente ao sexto ano de planejamento.

\begin{tabular}{ccccc}
\hline UG & Regime & $\begin{array}{c}\text { Área cortada } \\
\text { (ha) }\end{array}$ & $\begin{array}{c}\text { Volume total } \\
\text { de madeira }\left(\mathbf{m}^{\mathbf{3}}\right)\end{array}$ & Operação florestal \\
\hline 1 & 12 & 118,15 & 37571,70 & Reforma \\
3 & 12 & 22,46 & 6849,51 & Reforma \\
4 & 24 & 142,46 & 48295,40 & Reforma \\
14 & 17 & 104,69 & 27114,71 & Condução \\
25 & 30 & 51,51 & 16328,67 & Reforma \\
27 & 27 & 264,47 & 113984,67 & Condução \\
35 & 12 & 140,58 & 35846,63 & Reforma \\
35 & 13 & 298,63 & 76150,37 & Reforma \\
Total & & $\mathbf{1 1 4 2 , 9 4}$ & $\mathbf{3 6 2 1 4 1 , 6 5}$ & \\
\hline
\end{tabular}


Plano de colheita referente ao sétimo ano de planejamento.

\begin{tabular}{ccccc}
\hline UG & Regime & $\begin{array}{c}\text { Área cortada } \\
\text { (ha) }\end{array}$ & $\begin{array}{c}\text { Volume total } \\
\left.\text { de madeira } \mathbf{( m}^{\mathbf{3}}\right)\end{array}$ & Operação florestal \\
\hline 3 & 21 & 247,94 & 84052,78 & Reforma \\
3 & 26 & 104,20 & 35323,56 & Reforma \\
26 & 19 & 75,55 & 25384,80 & Reforma \\
27 & 61 & 55,65 & 23987,05 & Condução \\
30 & 61 & 30,76 & 10457,96 & Condução \\
35 & 25 & 118,01 & 33042,46 & Reforma \\
35 & 26 & 242,79 & 67980,44 & Reforma \\
36 & 20 & 17,36 & 5467,42 & Reforma \\
36 & 22 & 242,68 & 76445,18 & Reforma \\
Total & & $\mathbf{1 1 3 4 , 9 4}$ & $\mathbf{3 6 2 1 4 1 , 6 5}$ & \\
\hline
\end{tabular}

Plano de colheita referente ao oitavo ano de planejamento.

\begin{tabular}{ccccc}
\hline UG & Regime & $\begin{array}{c}\text { Área cortada } \\
(\mathbf{h a})\end{array}$ & $\begin{array}{c}\text { Volume total } \\
\text { de madeira }\left(\mathbf{m}^{\mathbf{3}}\right)\end{array}$ & Operação florestal \\
\hline 2 & 37 & 1,36 & 297,93 & Condução \\
6 & 67 & 2,11 & 447,47 & Condução \\
8 & 23 & 86,10 & 18511,50 & Reforma \\
17 & 37 & 92,84 & 22931,53 & Condução \\
17 & 65 & 372,48 & 82690,52 & Condução \\
21 & 39 & 82,00 & 17384,00 & Condução \\
22 & 21 & 78,98 & 26695,24 & Reforma \\
23 & 39 & 145,79 & 33385,91 & Condução \\
24 & 23 & 290,04 & 85271,76 & Reforma \\
29 & 38 & 159,52 & 27596,96 & Condução \\
30 & 67 & 118,26 & 40208,84 & Condução \\
33 & 23 & 30,00 & 6720,00 & Reforma \\
Total & & $\mathbf{1 4 5 9 , 4 8}$ & $\mathbf{3 6 2 1 4 1 , 6 6}$ & \\
\hline
\end{tabular}

Plano de colheita referente ao nono ano de planejamento.

\begin{tabular}{ccccc}
\hline UG & Regime & $\begin{array}{c}\text { Área cortada } \\
\text { (ha) }\end{array}$ & $\begin{array}{c}\text { Volume total } \\
\text { de madeira }\left(\mathbf{m}^{\mathbf{3}}\right)\end{array}$ & Operação florestal \\
\hline 2 & 68 & 37,97 & 8315,34 & Condução \\
5 & 69 & 139,00 & 25298,00 & Condução \\
6 & 69 & 209,12 & 49143,04 & Condução \\
7 & 69 & 156,13 & 29664,70 & Condução \\
9 & 45 & 261,62 & 86336,22 & Reforma \\
19 & 69 & 180,11 & 39263,98 & Condução \\
20 & 88 & 75,00 & 22725,00 & Reforma \\
28 & 78 & 137,63 & 40187,78 & Reforma \\
28 & 85 & 246,80 & 61207,59 & Condução \\
Total & & $\mathbf{1 4 4 3 , 3 9}$ & $\mathbf{3 6 2 1 4 1 , 6 5}$ & \\
\hline
\end{tabular}


Plano de colheita referente ao décimo ano de planejamento.

\begin{tabular}{ccccc}
\hline UG & Regime & $\begin{array}{c}\text { Área cortada } \\
\text { (ha) }\end{array}$ & $\begin{array}{c}\text { Volume total } \\
\left.\text { de madeira } \mathbf{( m}^{\mathbf{3}}\right)\end{array}$ & Operação florestal \\
\hline 9 & 61 & 46,16 & 15234,38 & Reforma \\
10 & 48 & 106,63 & 23245,69 & Condução \\
10 & 59 & 180,32 & 35343,43 & Condução \\
16 & 27 & 458,71 & 139905,79 & Reforma \\
18 & 53 & 171,50 & 47505,58 & Reforma \\
18 & 59 & 64,60 & 15180,93 & Condução \\
28 & 87 & 268,24 & 74033,05 & Condução \\
32 & 87 & 52,20 & 11692,80 & Condução \\
Total & & $\mathbf{1 3 4 8 , 3 6}$ & $\mathbf{3 6 2 1 4 1 , 6 5}$ & \\
\hline
\end{tabular}

Plano de colheita referente ao décimo primeiro ano de planejamento.

\begin{tabular}{ccccc}
\hline UG & Regime & $\begin{array}{c}\text { Área cortada } \\
(\mathbf{h a})\end{array}$ & $\begin{array}{c}\text { Volume total } \\
\text { de madeira }\left(\mathbf{m}^{\mathbf{3}}\right)\end{array}$ & Operação florestal \\
\hline 4 & 15 & 119,45 & 36430,94 & Reforma \\
9 & 63 & 61,66 & 22629,37 & Reforma \\
10 & 60 & 52,12 & 11363,21 & Condução \\
11 & 38 & 598,29 & 139401,92 & Condução \\
12 & 37 & 206,00 & 60358,00 & Reforma \\
13 & 15 & 41,07 & 14785,20 & Reforma \\
15 & 60 & 193,10 & 42675,10 & Condução \\
16 & 37 & 14,79 & 4511,71 & Reforma \\
31 & 20 & 123,40 & 29986,20 & Condução \\
Total & & $\mathbf{1 4 0 9 , 8 8}$ & $\mathbf{3 6 2 1 4 1 , 6 4}$ & \\
\hline
\end{tabular}

Plano de colheita referente ao décimo segundo ano de planejamento.

\begin{tabular}{|c|c|c|c|c|}
\hline UG & Regime & $\begin{array}{c}\text { Área cortada } \\
\text { (ha) }\end{array}$ & $\begin{array}{c}\text { Volume total } \\
\text { de madeira }\left(\mathrm{m}^{3}\right)\end{array}$ & Operação florestal \\
\hline 1 & 12 & 118,15 & 37571,70 & Reforma \\
\hline 3 & 12 & 22,46 & 6849,51 & Reforma \\
\hline 4 & 24 & 142,46 & 43451,61 & Reforma \\
\hline 11 & 39 & 68,80 & 17818,79 & Condução \\
\hline 14 & 17 & 104,69 & 28685,06 & Reforma \\
\hline 26 & 19 & 75,55 & 19718,55 & Reforma \\
\hline 27 & 27 & 264,47 & 70083,38 & Reforma \\
\hline 35 & 12 & 140,58 & 35846,63 & Reforma \\
\hline 35 & 13 & 298,63 & 76150,37 & Reforma \\
\hline 35 & 25 & 118,01 & 21713,62 & Condução \\
\hline 36 & 20 & 17,36 & 4252,44 & Reforma \\
\hline Total & & 1371,15 & 362141,66 & \\
\hline
\end{tabular}


Plano de colheita referente ao décimo terceiro ano de planejamento.

\begin{tabular}{ccccc}
\hline UG & Regime & $\begin{array}{c}\text { Área cortada } \\
\text { (ha) }\end{array}$ & $\begin{array}{c}\text { Volume total } \\
\text { de madeira } \mathbf{( m}^{\mathbf{3}} \mathbf{)}\end{array}$ & Operação florestal \\
\hline 2 & 37 & 1,36 & 281,60 & Reforma \\
3 & 21 & 247,94 & 75622,71 & Reforma \\
3 & 26 & 104,20 & 26987,62 & Condução \\
17 & 37 & 92,84 & 20424,84 & Reforma \\
17 & 65 & 372,48 & 81945,56 & Reforma \\
25 & 30 & 51,51 & 13856,19 & Condução \\
27 & 61 & 55,65 & 14748,42 & Reforma \\
30 & 61 & 30,76 & 6182,50 & Reforma \\
35 & 26 & 242,79 & 52684,84 & Condução \\
36 & 22 & 242,68 & 69407,37 & Reforma \\
Total & & $\mathbf{1 4 4 2 , 2 2}$ & $\mathbf{3 6 2 1 4 1 , 6 4}$ & \\
\hline
\end{tabular}

Plano de colheita referente ao décimo quarto ano de planejamento.

\begin{tabular}{ccccc}
\hline UG & Regime & $\begin{array}{c}\text { Área cortada } \\
\text { (ha) }\end{array}$ & $\begin{array}{c}\text { Volume total } \\
\text { de madeira }\left(\mathbf{m}^{\mathbf{3}}\right)\end{array}$ & Operação florestal \\
\hline 2 & 68 & 37,97 & 7859,71 & Reforma \\
6 & 67 & 2,11 & 525,56 & Reforma \\
8 & 23 & 86,10 & 14464,80 & Condução \\
9 & 45 & 261,62 & 61481,85 & Condução \\
20 & 88 & 75,00 & 16275,00 & Condução \\
21 & 39 & 82,00 & 18450,00 & Reforma \\
22 & 21 & 78,98 & 24009,92 & Reforma \\
23 & 39 & 145,79 & 35281,18 & Reforma \\
24 & 23 & 290,04 & 65259,00 & Condução \\
28 & 78 & 137,63 & 28626,92 & Condução \\
28 & 85 & 246,80 & 60467,18 & Reforma \\
30 & 67 & 118,26 & 23770,52 & Reforma \\
33 & 23 & 30,00 & 5670,00 & Condução \\
Total & & $\mathbf{1 5 9 2 , 3 1}$ & $\mathbf{3 6 2 1 4 1 , 6 4}$ & \\
\hline
\end{tabular}


ANEXO C - Plano de colheita resultante do Modelo 3

Plano de colheita referente ao primeiro ano de planejamento

\begin{tabular}{ccccc}
\hline UG & Regime & $\begin{array}{c}\text { Área cortada } \\
(\mathbf{h a})\end{array}$ & $\begin{array}{c}\text { Volume total } \\
\text { de madeira }\left(\mathbf{m}^{\mathbf{3}}\right)\end{array}$ & Operação florestal \\
\hline 6 & 20 & 55,54 & 13830,16 & Reforma \\
6 & 21 & 3,90 & 971,62 & Reforma \\
7 & 19 & 156,13 & 31382,13 & Reforma \\
8 & 20 & 86,10 & 17220,00 & Condução \\
17 & 3 & 128,00 & 33408,52 & Reforma \\
17 & 5 & 278,09 & 72582,51 & Reforma \\
17 & 19 & 6,17 & 1609,67 & Reforma \\
17 & 21 & 53,06 & 13847,82 & Reforma \\
19 & 20 & 180,11 & 41425,30 & Reforma \\
21 & 20 & 82,00 & 21976,00 & Reforma \\
22 & 21 & 78,98 & 26695,24 & Reforma \\
23 & 21 & 145,79 & 41987,52 & Reforma \\
29 & 20 & 159,52 & 32542,08 & Reforma \\
33 & 20 & 30,00 & 6330,00 & Condução \\
Total & & $\mathbf{1 4 4 3 , 3 9}$ & $\mathbf{3 5 5 8 0 8 , 5 7}$ & \\
\hline
\end{tabular}

Plano de colheita referente ao segundo ano de planejamento.

\begin{tabular}{ccccc}
\hline UG & Regime & $\begin{array}{c}\text { Área cortada } \\
\text { (ha) }\end{array}$ & $\begin{array}{c}\text { Volume total } \\
\text { de madeira }\left(\mathbf{m}^{\mathbf{3}}\right)\end{array}$ & Operação florestal \\
\hline 2 & 56 & 39,33 & 10107,81 & Reforma \\
5 & 56 & 139,00 & 29746,00 & Reforma \\
6 & 56 & 151,79 & 42044,47 & Reforma \\
24 & 56 & 290,04 & 85271,76 & Reforma \\
27 & 61 & 56,87 & 24511,19 & Reforma \\
27 & 65 & 224,69 & 96840,48 & Reforma \\
27 & 69 & 38,56 & 16620,05 & Reforma \\
30 & 69 & 149,02 & 50666,80 & Reforma \\
Total & & $\mathbf{1 0 8 9 , 3 0}$ & $\mathbf{3 5 5 8 0 8 , 5 6}$ & \\
\hline
\end{tabular}

Plano de colheita referente ao terceiro ano de planejamento.

\begin{tabular}{ccccc}
\hline UG & Regime & $\begin{array}{c}\text { Área cortada } \\
\text { (ha) }\end{array}$ & $\begin{array}{c}\text { Volume total } \\
\text { de madeira }\left(\mathbf{m}^{\mathbf{3}}\right)\end{array}$ & Operação florestal \\
\hline 9 & 44 & 317,08 & 104635,01 & Reforma \\
20 & 87 & 55,17 & 18592,46 & Reforma \\
20 & 90 & 19,83 & 6682,54 & Reforma \\
28 & 80 & 652,67 & 212117,75 & Reforma \\
32 & 80 & 52,20 & 13780,80 & Reforma \\
Total & & $\mathbf{1 0 9 6 , 9 5}$ & $\mathbf{3 5 5 8 0 8 , 5 6}$ & \\
\hline
\end{tabular}


Plano de colheita referente ao quarto ano de planejamento.

\begin{tabular}{ccccc}
\hline UG & Regime & $\begin{array}{c}\text { Área cortada } \\
\text { (ha) }\end{array}$ & $\begin{array}{c}\text { Volume total } \\
\text { de madeira }\left(\mathbf{m}^{\mathbf{3}}\right)\end{array}$ & Operação florestal \\
\hline 9 & 61 & 52,37 & 19221,33 & Reforma \\
10 & 55 & 339,08 & 87143,56 & Reforma \\
11 & 23 & 386,66 & 105943,99 & Reforma \\
11 & 25 & 75,09 & 20574,91 & Reforma \\
15 & 55 & 193,10 & 50206,00 & Reforma \\
18 & 55 & 236,10 & 72718,80 & Reforma \\
Total & & $\mathbf{1 2 8 2 , 4 0}$ & $\mathbf{3 5 5 8 0 8 , 5 9}$ & \\
\hline
\end{tabular}

Plano de colheita referente ao quinto ano de planejamento.

\begin{tabular}{ccccc}
\hline UG & Regime & $\begin{array}{c}\text { Área cortada } \\
\text { (ha) }\end{array}$ & $\begin{array}{c}\text { Volume total } \\
\text { de madeira }\left(\mathbf{m}^{\mathbf{3}}\right)\end{array}$ & Operação florestal \\
\hline 4 & 15 & 135,14 & 41218,58 & Reforma \\
11 & 33 & 193,19 & 58922,71 & Reforma \\
11 & 35 & 12,15 & 3706,70 & Reforma \\
12 & 39 & 206,00 & 67156,00 & Reforma \\
14 & 11 & 104,69 & 24288,08 & Condução \\
16 & 39 & 473,50 & 160516,50 & Reforma \\
Total & & $\mathbf{1 1 2 4 , 6 8}$ & $\mathbf{3 5 5 8 0 8 , 5 7}$ & \\
\hline
\end{tabular}

Plano de colheita referente ao sexto ano de planejamento.

\begin{tabular}{ccccc}
\hline UG & Regime & $\begin{array}{c}\text { Área cortada } \\
\text { (ha) }\end{array}$ & $\begin{array}{c}\text { Volume total } \\
\text { de madeira }\left(\mathbf{m}^{\mathbf{3}}\right)\end{array}$ & Operação florestal \\
\hline 1 & 12 & 118,15 & 37571,70 & Reforma \\
3 & 14 & 374,60 & 114253,00 & Reforma \\
4 & 24 & 126,77 & 42974,05 & Reforma \\
13 & 24 & 41,07 & 16469,07 & Reforma \\
17 & 3 & 128,00 & 28160,44 & Reforma \\
17 & 5 & 278,09 & 61180,66 & Reforma \\
25 & 26 & 51,51 & 16328,67 & Reforma \\
31 & 26 & 123,40 & 38871,00 & Reforma \\
Total & & $\mathbf{1 2 4 1 , 5 9}$ & $\mathbf{3 5 5 8 0 8 , 5 8}$ & \\
\hline
\end{tabular}

Plano de colheita referente ao sétimo ano de planejamento.

\begin{tabular}{ccccc}
\hline UG & Regime & $\begin{array}{c}\text { Área cortada } \\
\text { (ha) }\end{array}$ & $\begin{array}{c}\text { Volume total } \\
\text { de madeira }\left(\mathbf{m}^{\mathbf{3}}\right)\end{array}$ & Operação florestal \\
\hline 26 & 27 & 75,55 & 25384,80 & Reforma \\
27 & 61 & 56,87 & 24511,19 & Condução \\
35 & 27 & 800,00 & 224000,00 & Reforma \\
36 & 27 & 260,04 & 81912,60 & Reforma \\
Total & & $\mathbf{1 1 9 2 , 4 6}$ & $\mathbf{3 5 5 8 0 8 , 5 9}$ & \\
\hline
\end{tabular}


Plano de colheita referente ao oitavo ano de planejamento.

\begin{tabular}{ccccc}
\hline UG & Regime & $\begin{array}{c}\text { Área cortada } \\
\text { (ha) }\end{array}$ & $\begin{array}{c}\text { Volume total } \\
\left.\text { de madeira } \mathbf{( m}^{\mathbf{3}}\right)\end{array}$ & Operação florestal \\
\hline 6 & 20 & 55,54 & 15385,36 & Reforma \\
6 & 21 & 3,90 & 1080,88 & Reforma \\
7 & 19 & 156,13 & 34973,12 & Reforma \\
8 & 20 & 86,10 & 18511,50 & Reforma \\
17 & 19 & 6,17 & 1794,68 & Reforma \\
17 & 21 & 53,06 & 15439,53 & Reforma \\
19 & 20 & 180,11 & 46108,16 & Reforma \\
21 & 20 & 82,00 & 20500,00 & Reforma \\
22 & 21 & 78,98 & 26695,24 & Reforma \\
23 & 21 & 145,79 & 39217,51 & Reforma \\
27 & 65 & 224,69 & 96840,48 & Condução \\
29 & 20 & 159,52 & 32542,08 & Reforma \\
33 & 20 & 30,00 & 6720,00 & Reforma \\
Total & & $\mathbf{1 2 6 1 , 9 9}$ & $\mathbf{3 5 5 8 0 8 , 5 5}$ & \\
\hline
\end{tabular}

Plano de colheita referente ao nono ano de planejamento.

\begin{tabular}{ccccc}
\hline UG & Regime & $\begin{array}{c}\text { Área cortada } \\
(\mathbf{h a})\end{array}$ & $\begin{array}{c}\text { Volume total } \\
\text { de madeira }\left(\mathbf{m}^{\mathbf{3}}\right)\end{array}$ & Operação florestal \\
\hline 2 & 56 & 39,33 & 10107,81 & Reforma \\
5 & 56 & 139,00 & 29746,00 & Reforma \\
6 & 56 & 151,79 & 42044,47 & Reforma \\
9 & 44 & 317,08 & 104635,01 & Reforma \\
20 & 87 & 55,17 & 16716,66 & Reforma \\
24 & 56 & 290,04 & 85271,76 & Reforma \\
27 & 69 & 38,56 & 16620,05 & Condução \\
30 & 69 & 149,02 & 50666,80 & Condução \\
Total & & $\mathbf{1 1 7 9 , 9 8}$ & $\mathbf{3 5 5 8 0 8 , 5 7}$ & \\
\hline
\end{tabular}

Plano de colheita referente ao décimo ano de planejamento.

\begin{tabular}{ccccc}
\hline UG & Regime & $\begin{array}{c}\text { Área cortada } \\
(\mathbf{h a})\end{array}$ & $\begin{array}{c}\text { Volume total } \\
\text { de madeira }\left(\mathbf{m}^{\mathbf{3}}\right)\end{array}$ & Operação florestal \\
\hline 9 & 61 & 52,37 & 17283,49 & Reforma \\
11 & 23 & 386,66 & 105943,99 & Reforma \\
20 & 90 & 19,83 & 6682,54 & Reforma \\
28 & 80 & 652,67 & 212117,75 & Reforma \\
32 & 80 & 52,20 & 13780,80 & Reforma \\
Total & & $\mathbf{1 1 6 3 , 7 3}$ & $\mathbf{3 5 5 8 0 8 , 6 0}$ & \\
\hline
\end{tabular}


Plano de colheita referente ao décimo primeiro ano de planejamento.

\begin{tabular}{ccccc}
\hline UG & Regime & $\begin{array}{c}\text { Área cortada } \\
\text { (ha) }\end{array}$ & $\begin{array}{c}\text { Volume total } \\
\left.\text { de madeira } \mathbf{( m}^{\mathbf{3}}\right)\end{array}$ & Operação florestal \\
\hline 4 & 15 & 135,14 & 41218,58 & Reforma \\
10 & 55 & 339,08 & 87143,56 & Reforma \\
11 & 25 & 75,09 & 22902,72 & Reforma \\
11 & 33 & 193,19 & 52933,84 & Reforma \\
14 & 11 & 104,69 & 28685,06 & Reforma \\
15 & 55 & 193,10 & 50206,00 & Reforma \\
18 & 55 & 236,10 & 72718,80 & Reforma \\
Total & & $\mathbf{1 2 7 6 , 3 9}$ & $\mathbf{3 5 5 8 0 8 , 5 7}$ & \\
\hline
\end{tabular}

Plano de colheita referente ao décimo segundo ano de planejamento.

\begin{tabular}{ccccc}
\hline UG & Regime & $\begin{array}{c}\text { Área cortada } \\
(\mathbf{h a})\end{array}$ & $\begin{array}{c}\text { Volume total } \\
\text { de madeira }\left(\mathbf{m}^{\mathbf{3}}\right)\end{array}$ & Operação florestal \\
\hline 1 & 12 & 118,15 & 37571,70 & Reforma \\
4 & 24 & 126,77 & 38663,97 & Reforma \\
11 & 35 & 12,15 & 3706,70 & Reforma \\
12 & 39 & 206,00 & 67156,00 & Reforma \\
13 & 24 & 41,07 & 14785,20 & Reforma \\
16 & 39 & 473,50 & 160516,50 & Reforma \\
17 & 3 & 128,00 & 33408,52 & Reforma \\
Total & & $\mathbf{1 1 0 5 , 6 4}$ & $\mathbf{3 5 5 8 0 8 , 5 8}$ & \\
\hline
\end{tabular}

Plano de colheita referente ao décimo terceiro ano de planejamento.

\begin{tabular}{ccccc}
\hline UG & Regime & $\begin{array}{c}\text { Área cortada } \\
\text { (ha) }\end{array}$ & $\begin{array}{c}\text { Volume total } \\
\left.\text { de madeira } \mathbf{( m}^{\mathbf{3}}\right)\end{array}$ & Operação florestal \\
\hline 3 & 14 & 374,60 & 126989,40 & Reforma \\
7 & 19 & 156,13 & 26385,97 & Reforma \\
17 & 5 & 278,09 & 80925,32 & Reforma \\
17 & 19 & 6,17 & 1356,81 & Reforma \\
25 & 26 & 51,51 & 16328,67 & Reforma \\
27 & 61 & 56,87 & 15070,68 & Reforma \\
27 & 65 & 224,69 & 49880,71 & Reforma \\
31 & 26 & 123,40 & 38871,00 & Reforma \\
Total & & $\mathbf{1 2 7 1 , 4 6}$ & $\mathbf{3 5 5 8 0 8 , 5 7}$ & \\
\hline
\end{tabular}


Plano de colheita referente ao décimo quarto ano de planejamento.

\begin{tabular}{ccccc}
\hline UG & Regime & $\begin{array}{c}\text { Área cortada } \\
\text { (ha) }\end{array}$ & $\begin{array}{c}\text { Volume total } \\
\text { de madeira }\left(\mathbf{m}^{\mathbf{3}}\right)\end{array}$ & Operação florestal \\
\hline 6 & 21 & 3,90 & 971,62 & Reforma \\
17 & 21 & 53,06 & 13847,82 & Reforma \\
22 & 21 & 78,98 & 24009,92 & Reforma \\
23 & 21 & 145,79 & 35281,18 & Reforma \\
26 & 27 & 75,55 & 21607,30 & Condução \\
35 & 27 & 800,00 & 190400,00 & Condução \\
36 & 27 & 260,04 & 69690,72 & Condução \\
Total & & $\mathbf{1 4 1 7 , 3 2}$ & $\mathbf{3 5 5 8 0 8 , 5 7}$ & \\
\hline
\end{tabular}




\section{REFERÊNCIAS BIBLIOGRÁFICAS}

AHRENS, S. O manejo de recursos florestais no Brasil: conceitos, realidades e perspectivas. Documentos EMBRAPA CNPF, n.34, p.5-16, 1997.

BORGES, J.G. Paradigmas, tecnologias e equívocos em gestão de recursos florestais. Revista Florestal, v.12, n.1/2, p.83-92, 1999.

BORGES, J.G. Sistema de apoio à decisão em planeamento em recursos naturais e ambiente. Revista Florestal, v.9, n.3, p.37-44, 1996.

BRASIL. Ministério das Minas e Energia. Projeto RADAMBRASIL. Folha SF 23/24

Rio de Janeiro/Vitória. Rio de Janeiro, 1983. (Levantamento de Recursos Naturais, 32)

CARVALHO, P.O. Gestão florestal sustentável e certificação. Revista Florestal, v.11, n.1, p.16-21,1998.

DAVIS, L.S; JOHNSON, K.N. Forest management. 3.ed. New York: McGraw-Hill, 1987. $790 \mathrm{p}$.

DEPARTAMENTO DE ÁGUA E ENERGIA ELÉTRICA. Totais mensais de chuva do Estado de São Paulo 1976 -1991. São Paulo, 1993. 
FALCÃO, A.; BORGES, J.G. Programação linear e gestão estratégica em recursos florestais. Revista Florestal, v.12, n1/2, p.93-98, 1999.

FLORIN, Levantamento agroecológico das áreas da FLORIN no Vale do Paraíba: relatório interno. Jacareí, 1988. 151p.

HORNBECK, J.W.; SMITH,R.B. A water resources decision model for forest managers. Agricultural and Forest Meteorology, v.84, p.83-88, 1997.

LIMA, W.P. Impacto ambiental do eucalipto, 2.ed. São Paulo: EDUSP, 1996. 301p.

LIMA, W.P. Indicadores hidrológicos no manejo sustentável de plantações de eucalipto. In: IUFRO CONFERENCE ON SILVICULTURE AND IMPROVEMENT OF EUCALYPTS, Salvador, 1997. Anais. Colombo: EMBRAPA CNPF, 1997. v.4, p.12-29.

LIMA, W.P.; ZAKIA, M.J.B. Monitoramento de bacias hidrográficas em áreas florestadas. Série Técnica IPEF, v.10, n.29, p.11-21, abr.1996.

LIMA, W.P.; ZAKIA, M.J.B. Indicadores hidrológicos em áreas florestais. Série Técnica IPEF, v.12, n.31, p.53-64, abr.1998.

MARQUES, J.F.; COMUNE, A.E. Economia do meio ambiente - teoria, políticas e a gestão de espaços regionais: a teoria neoclássica e a valoração ambiental. Campinas: UNICAMP, Instituto de Economia, 1997.

MIRAGAIA, C.; BORGES, J.G.; TOMÉ, M. Inflor, um sistema de informação em recursos florestais. Revista Florestal, v.12, n.1/2, p.51-56, 1999. 
MUSETTI, R.A. Da proteção jurídica ambiental dos recursos hídricos. Leme: Editora de Direito, 2001. 377p.

NASCIMENTO,C.M.; PEREIRA,M.A.M.G. Atlas climatológico do Estado de São Paulo (1977-1978). Campinas: Fundação Cargill, 1988. 93p.

NOBRE, S.R; RODRIGUEZ, L.C.E Um método para composição e avaliação econômica de regimes de talhadia simples. Scientia Forestalis, n.60, dez. 2001./No prelo/

RANZINI, M. Balanço Hídrico, ciclagem geoquímica de nutrientes e perdas de solo em duas microbacias reflorestadas com Eucalyptus saligna Smith. no Vale do Paraíba, SP. Piracicaba, 1990, 99p. Dissertação (Mestrado) - Escola Superior de Agricultura 'Luiz de Queiroz", Universidade de São Paulo.

RODRIGUEZ,L.C.E. Gerenciamento da produção florestal. Documentos Florestais, v.13, p.1-41, maio1991.

RODRIGUEZ, L.C.E; BORGES, J.G.C; Técnicas matemáticas para determinação de níveis sustentáveis de produção em eucaliptais. Revista Florestal, v.12, n.1/2, p.8392, 1999.

RODRIGUEZ, L.C.E; BUENO, A.R.S.; RODRIGUES,F.; Rotações de eucaliptos mais longas: análise volumétrica e econômica. Scientia Forestalis, n.51, p.15-28, jun. 1997.

SALATI, E.; LEMOS H.M.; SALATI, E. Água e o desenvolvimento sustentável. In: REBOUÇAS, A.C.; BRAGA, B.; TUNDISI, J.G. Águas doces do Brasil. São Paulo: Escrituras Editora, 1999. cap.2, p. 39-64. 
SMITH, C.; THWAITES, R. Forest TIM: evaluating plantation forest land management by identifying unsustainable practices. Australian Forestry, v.61. n.2, p.89-102, Feb. 1998.

STEDNICK, J. D. Monitoring the effects of timber harvest on annual water yield. Journal of Hydrology, v.176, p.79-85, 1996.

TUCCI, C.E.M. Modelos hidrológicos. Porto Alegre: Editora da Universidade, 1998. $669 \mathrm{p}$.

VARMA, V.K.; FERGUSON, I.; WILD, I. Decision support system for the sustainable forest management. Forest Ecology and Management, v.128, n.1/2, p.49-55, Mar.2000.

VITAL, A.R.T. Efeito do corte raso no balanço hídrico e na ciclagem de nutrientes em uma microbacia reflorestada com eucalipto. Piracicaba, 1996, 106p. Dissertação (Mestrado) - Escola Superior de Agricultura "Luiz de Queiroz", Universidade de São Paulo. 